(2) Open Access Full Text Article

\title{
Gemcitabine hydrochloride microspheres used for intravesical treatment of superficial bladder cancer: a comprehensive in vitro/ex vivo/in vivo evaluation
}

This article was published in the following Dove Press journal:

Drug Design, Development and Therapy

\author{
Sinem Yaprak Karavana' \\ Zeynep Ay Șenyiğit ${ }^{2}$ \\ Çağrı Çalıșkan ${ }^{3}$ \\ Gülnur Sevin ${ }^{4}$ \\ Derya İlem Özdemir ${ }^{2}$ \\ Yalçın Erzurumlu ${ }^{5}$ \\ Sait Șen ${ }^{6}$ \\ Esra Baloğlu' \\ 'Department of Pharmaceutical \\ Technology, Faculty of Pharmacy, Ege \\ University, Izmir, Turkey; ${ }^{2}$ Department \\ of Pharmaceutical Technology, Faculty \\ of Pharmacy, Izmir Katip Çelebi \\ University, Izmir, Turkey; ${ }^{3}$ Department \\ of Radiopharmacy, Faculty of \\ Pharmacy, Ege University, Izmir, Turkey; \\ ${ }^{4}$ Department of Pharmacology, Faculty \\ of Pharmacy, Ege University, Izmir, \\ Turkey; ${ }^{5}$ Department of Biochemistry, \\ Faculty of Pharmacy, Ege University, \\ Izmir, Turkey; ${ }^{6}$ Department of \\ Pathology, Faculty of Medicine, Ege \\ University, Izmir, Turkey
}

\footnotetext{
Correspondence: Sinem Yaprak Karavana Department of Pharmaceutical Technology, Faculty of Pharmacy, Ege University, Erzene Mahallesi, Gençlik Caddesi Ege Üniversitesi Kampüsü, Bornova, Izmir 35040, Turkey Email sinemyaprak@hotmail.com
}

\begin{abstract}
Introduction: Bladder cancer is responsible for more than 130,000 deaths annually worldwide. Intravesical delivery of chemotherapeutic agents provides effective drug localization to the target area to reduce toxicity and increase efficacy. This study aimed to develop an intravesical delivery system of gemcitabine $\mathrm{HCl}(\mathrm{Gem}-\mathrm{HCl})$ to provide a sustained-release profile, to prolong residence time, and to enhance its efficiency in the treatment of bladder cancer.
\end{abstract}

Materials and methods: For this purpose, bioadhesive microspheres were successfully prepared with average particle size, encapsulation efficiency, and loading capacity of $98.4 \mu \mathrm{m}$, $82.657 \% \pm 5.817 \%$, and $12.501 \pm 0.881 \mathrm{mg}$, respectively. For intravesical administration, bioadhesive microspheres were dispersed in mucoadhesive chitosan or in situ poloxamer gels and characterized in terms of gelation temperature, viscosity, mechanical, syringeability, and bioadhesive and rheological properties. The cytotoxic effects of $\mathrm{Gem}-\mathrm{HCl}$ solution, $\mathrm{Gem}-\mathrm{HCl}$ microspheres, and $\mathrm{Gem}-\mathrm{HCl}$ microsphere-loaded gel formulations were evaluated in two different bladder cancer cell lines: T24 (ATCC HTB4TM) and RT4 (ATCC HTB2TM).

Results: According to cell-culture studies, Gem-HCl microsphere-loaded poloxamer gel was more cytotoxic than $\mathrm{Gem}-\mathrm{HCl}$ microsphere-loaded chitosan gel. Antitumor efficacy of newly developed formulations were investigated by in vivo studies using bladder-tumorinduced rats.

Conclusion: According to in vivo studies, $\mathrm{Gem}-\mathrm{HCl}$ microsphere-loaded poloxamer gel was found to be an effective and promising alternative for current intravesical delivery-system therapies.

Keywords: gemcitabine $\mathrm{HCl}$, intravesical chemotherapy, superficial bladder cancer microspheres, mucoadhesive gel, in situ gel

\section{Introduction}

Although intensive research on cancer therapy, such as on surgery, radiotherapy, and chemotherapy, has been carried out, cancer still has high worldwide mortality. ${ }^{1-3}$ Bladder cancer is the ninth-most commonly diagnosed cancer in the world for both sexes and the second-most common malignancy of the urogenital tract. ${ }^{4}$ It is relatively common in more developed regions, and occurs among men more than women. The worldwide incidence rate for bladder cancer is 8.9 for men and 2.2 for women (sex ratio 4.04:1), but the reasons for this sex difference are still unclear. ${ }^{5}$ More than $70 \%$ of bladder cancers are noninvasive or superficially invasive at diagnosis. Transurethral resection of the tumor is the first-choice treatment for such patients, but it 
commonly results in tumor relapse, and thus more aggressive therapies are needed. ${ }^{6-8}$ Although a number of treatment strategies, including systemic immunotherapy/chemotherapy and radiotherapy, have been used recently, the overall survival rate has not improved, and bladder cancer is associated with serious morbidity and even mortality. Therefore, it is clear that alternative treatment approaches for bladder cancer are still needed. ${ }^{9,10}$

Intravesical therapy has the potential to be an alternative to the treatment of superficial bladder cancer. During this treatment, drugs are instilled directly into the bladder through a catheter. It ensures high drug concentrations in tumor-bearing bladder tissue while reducing systemic exposure and adverse effects. The most common agents for intravesical application for bladder cancer are immunotherapeutic (bacillus Calmette-Guérin) and chemotherapeutic (thiotepa, mitomycin C, doxorubicin, and epirubicin) agents. Unfortunately, these agents have been shown to achieve complete response of $34 \%-53 \%$, and there is still a need for more effective chemotherapeutic agents for intravesical treatment of superficial bladder cancer. ${ }^{11}$

Gemcitabine hydrochloride (Gem-HCl; 2',2'-difluorodeoxycytidine) is a water-soluble pyrimidine analogue with a broad spectrum of antitumor activity, and when given intravesically it has been shown to produce good response rates for the treatment of superficial bladder cancer. ${ }^{12,13}$ It is transported into the cell, phosphorylated, and incorporated into DNA and RNA, which causes inhibition of growth activity and mediates apoptosis. ${ }^{14}$ The success of intravesical chemotherapy with $\mathrm{Gem}-\mathrm{HCl}$ depends on direct contact between the drug and the abnormal urothelium. Therefore, mechanisms that prolong exposure of the urothelium to the drug are expected to increase the efficacy of the treatment. ${ }^{15,16}$ For this purpose, several intravesical drug-delivery systems have been developed; however, these carriers are generally maintained intravesically for approximately 2 hours, due to washout by urine. ${ }^{17}$ This limitation can be avoided by the use of mucoadhesive drug-delivery systems, and mucoadhesion characteristics can be coupled with particulate systems, such as liposomes, nanoparticles, or microspheres (MSs). ${ }^{18}$ Among these systems, MSs have larger dimensions that ensure higher loading capacity. Also, when they are prepared with mucoadhesive polymers, they increase residence time, due to strong adhesion to the mucosa. However, to be administered intravesically, MSs need to be dispersed in liquids (ie, physiological serum) or in gel systems (ie, in situ or mucoadhesive gels). In situ gels are liquid formulations at storage conditions, but when administered in vivo, they transform into a gel at the target site with responses to various environmental conditions. ${ }^{19}$ Mucoadhesive gel systems can extend drug exposure in the bladder cavity beyond the voiding of urine and are capable of sustaining the release of active substances, ensuring highly desirable effects. ${ }^{20}$

The primary aim of this study was to develop bioadhesive Gem-HCl MSs prepared with Carbopol 2020 NF and Eudragit E100 (EE100) for the intravesical treatment of superficial bladder cancer. Afterward, MSs were dispersed in in situ poloxamer (Plx) gel or mucoadhesive chitosan (Chi) gel to prolong intravesical residence time, provide sustained release, and enhance efficiency. Finally, cytotoxic effects of Gem-HCl-loaded formulations were evaluated in T24 and RT4 bladder cancer cell lines and the efficacy of formulations histopathologically evaluated in male rats with an experimental non-muscle-invasive bladder cancer model.

\section{Materials and methods}

Gem-HCl was purchased from Sun Pharmaceutical Industries (Mumbai, India). Chi (high molecular weight) was purchased from Sigma-Aldrich (St Louis, MO, USA). Plx 188 and Plx 407 were kind gifts from BASF Chemicals (Ludwigshafen, Germany). EE100 and Carbopol 2020 NF were gifts from Evonik Industries (Essen, Germany) and Lubrizol (Wickliffe, OH, USA), respectively. Magnesium stearate was purchased from ZAG Laboratories (Istanbul, Turkey). All other chemicals were of analytical grade.

\section{Fourier-transform infrared spectrum analysis}

Gem-HCl, EE100, Carbopol 2020 NF, and their mixtures were homogeneously mixed with potassium bromide and the resulting powder mixture compressed under pressure for Fourier-transform infrared (FTIR) spectrum analysis. The disks obtained were scanned at $600-4,000 \mathrm{~cm}^{-1}$ wavelength and spectra obtained using IR spectrometry (Spectrum 100; PerkinElmer, Waltham, MA, USA).

\section{Preparation of microspheres}

MSs were prepared according to the solvent-evaporation method. ${ }^{15}$ Briefly, $1.5 \mathrm{~g}$ EE100 was dissolved in $8 \mathrm{~mL}$ acetone, and $1 \mathrm{~g}$ Carbopol $2020 \mathrm{NF}$ was added as powder. Suspension of $0.3 \mathrm{~g}$ magnesium stearate and $0.5 \mathrm{~g} \mathrm{Gem}-\mathrm{HCl}$ in $4 \mathrm{~mL}$ acetone was prepared separately and added to the polymer dispersion. The homogeneous final dispersion was cooled to $5^{\circ} \mathrm{C}$ and poured slowly with stirring at $750 \mathrm{rpm}$ into $80 \mathrm{~mL}$ liquid paraffin, which had previously also been cooled to $5^{\circ} \mathrm{C}$. The obtained emulsion was stirred at $40^{\circ} \mathrm{C}$ for 
50 minutes. After being cooled to room temperature, $10 \mathrm{~mL}$ $n$-hexane was added to the emulsion and stirring continued at $750 \mathrm{rpm}$ for 10 minutes. The MS suspension in liquid paraffin was filtered and MSs washed with $50 \mathrm{~mL} n$-hexane five times and dried at room temperature overnight. MSs were sieved and $125 \mu \mathrm{m}$ used for further testing because of high production yield. ${ }^{15}$

\section{Characterization of microspheres Particle-size distribution}

Mean diameters of MSs were determined with a Mastersizer 3000 (Hydro EV; Malvern Instruments, Malvern, UK). During measurements, they were dispersed in $n$-hexane and stirred at 2,000 rpm. All trials were run in triplicate.

\section{Scanning electron microscopy}

MSs were mounted onto an aluminum stub, sputter-coated with gold palladium $(\mathrm{Au} / \mathrm{Pd})$ using a vacuum evaporator, and surface morphology was examined by scanning electron microscopy (Phillips XL-30S FEG).

\section{Encapsulation efficiency and drug loading of microspheres}

Drug-loaded MSs (2 mg) were dissolved in $2 \mathrm{mg}$ ammonium acetate buffer solution ( $\mathrm{pH} 5.5$ ) and mixed at $100 \mathrm{rpm}$ for 24 hours at room temperature with incubator shaker (Lab-Line MaxQ 6000). The solution was filtered through a $0.22 \mu \mathrm{m}$ syringe filter and the filtrate analyzed by ultraperformance liquid chromatography (UPLC) to determine the amount of Gem-HCl loaded in the MSs. Encapsulation efficiency and drug loading were calculated:

$$
\begin{aligned}
& \text { Encapsulation efficiency } \\
& =\frac{\text { Total Gem } \mathrm{HCl}-\text { Free Gem } \mathrm{HCl}}{\text { Total Gem } \mathrm{HCl}} \times 100
\end{aligned}
$$

$$
\begin{aligned}
& \text { Drug loading } \\
& \qquad=\frac{\text { Total Gem } \mathrm{HCl}-\text { Free Gem } \mathrm{HCl}}{\text { Total amount of formulation components }} \times 100
\end{aligned}
$$

Gem-HCl was determined with a validated UPLC method on a Hypersil Gold $(100 \times 2.1 \mathrm{~mL}, 3 \mu \mathrm{m})$ column at $25^{\circ} \mathrm{C}$. Acetonitril:ammonium acetate buffer solution $(\mathrm{pH} 5.5$, 2.5:97.5 v:v) was used as the mobile phase at a flow rate of $400 \mu \mathrm{L} / \mathrm{min}$. Retention of $\mathrm{Gem}-\mathrm{HCl}$ was 1.78 minutes at $268 \mu \mathrm{m}$, while total analysis took 5 minutes. The calibration curve of $\mathrm{Gem}-\mathrm{HCl}$ was linear $\left(2-10 \mu \mathrm{g} / \mathrm{mL}, r^{2}=0.9996\right)$. Limits of detection and quantification were $0.0625 \mu \mathrm{g} / \mathrm{mL}$ and $0.2083 \mu \mathrm{g} / \mathrm{mL}$, respectively. All other validation data, such as intra- and interday precision, accuracy, selectivity, and stability, were within the limits.

\section{Preparation of Chi and Plx gels}

Mucoadhesive Chi gel was prepared by dissolving $2 \%$ (w:w) Chi in lactic acid solution. ${ }^{21}$ The gel was left at room temperature until the solution became clear. After 24 hours, microparticles (MPs) were suspended in the gel formulation with continuous stirring until a homogeneous mixture had been produced (10 mg MPs and $2 \mathrm{~g}$ gel). In situ Plx gel was prepared by adding Plx 407 (20\% w:w) and Plx 188 $(10 \% \mathrm{w}: \mathrm{w})$ to distilled water at $4^{\circ} \mathrm{C}$ with continuous stirring (cold method). The gel was left at $4^{\circ} \mathrm{C}$ until it became clear. After 24 hours, MPs were suspended in the gel formulation with continuous stirring until a homogeneous mixture had been produced (10 $\mathrm{mg}$ MPs and $2 \mathrm{~g}$ of gel). ${ }^{22,23}$

\section{Dilution of Chi and Plx gels with Tyrode solution}

Mucoadhesive Chi gel and in situ Plx gel were diluted with Tyrode solution (used as artificial urine) ${ }^{24}$ at a $1: 1$ ratio to mimic in vivo conditions of the bladder. Subsequently, the diluted gels were characterized in detail to evaluate changes in their structure when they were mixed with urine.

\section{Characterization of gels}

\section{Gelation temperature and time of in situ Plx gels}

Gelation temperature and time of in situ Plx gels were determined from oscillation measurements (Haake Mars rheometer, AR 2000; Thermo Fisher Scientific, Waltham, MA, USA) using a stainless-steel probe (plate/plate, $35 \mathrm{~mm}$ ). Samples were heated at $7^{\circ} \mathrm{C}-70^{\circ} \mathrm{C}$ at a rate of $2^{\circ} \mathrm{C} / \mathrm{min}$. The temperature versus viscosity $\left(\eta^{\prime}\right)$ graph was plotted and the gel-transition point defined as halfway between the viscosity of the solution and the viscosity of the gel form $(n=6){ }^{25}$

Mechanical, syringeability, and bioadhesive properties Mechanical, syringeability, and bioadhesive properties of formulations were determined using a software-controlled penetrometer (TA-XT Plus texture analyzer; Stable Micro Systems, Godalming, UK) with a $0.5 \mathrm{~kg}$ load cell. For determination of mechanical properties, an analytical probe (10 $\mathrm{mm}$ diameter) was compressed twice into formulations to a defined depth at a constant rate $(2 \mathrm{~mm} / \mathrm{s})$ at both $25^{\circ} \mathrm{C}$ and $37^{\circ} \mathrm{C}$. Mechanical parameters (hardness, adhesiveness, compressibility, cohesiveness, and elasticity) were calculated from the obtained force-time curves $(n=6) .{ }^{26}$ Syringeability was determined as the required work to expel formulations from a syringe, and was measured using a force transducer. 
Formulations were packed into plastic syringes connected to a catheter, and the plunger of the syringe was pushed at a constant force $(0.5 \mathrm{~N})$. Resistance to expressing the formulations through the catheter was derived from the area under the force-time curves at $25^{\circ} \mathrm{C} \pm 0.1{ }^{\circ} \mathrm{C}(\mathrm{n}=6) .{ }^{27}$

Bioadhesive properties of formulations were determined using bovine mucosal bladder tissue obtained from a local slaughterhouse. Mucosal membrane sections were attached to the holder of the texture analyzer at $37^{\circ} \mathrm{C}$. Gels were placed at the lower end of the probe and the probe lowered onto the bladder mucosa surface at a constant speed $(1 \mathrm{~mm} / \mathrm{s})$. Contact force $(0.05 \mathrm{~N})$ was applied for 2 minutes, after which the probe was moved upward. The area under the curve (mucoadhesion) was determined from the resultant force-distance graph $(\mathrm{n}=6) .{ }^{16}$

\section{Viscosity studies}

The experimental setup for measuring the effective viscosity of formulations consists of a sine-wave viscometer (Vibro SV-10) with a measurement range of 10-10,000 $\mathrm{mPa} \cdot \mathrm{s}$. The viscosity produced between the sensor plates of the viscometer and the sample fluid was measured at $25^{\circ} \mathrm{C}$ and $37^{\circ} \mathrm{C} \pm 0.1^{\circ} \mathrm{C}(\mathrm{n}=6) .{ }^{28}$

\section{Rheological measurements}

Rheological properties of formulations were characterized using a Haake Mars AR 2000 rheometer at $25^{\circ} \mathrm{C}$ and $37^{\circ} \mathrm{C} \pm 0.1^{\circ} \mathrm{C}$. Continuous-shear analysis of formulations were performed in flow mode with a parallel steel geometry plate (diameter $35 \mathrm{~mm}, 0.3 \mathrm{~mm}$ gap). Formulations were applied to the lower plate of the rheometer and flow curves measured over a range of shear rates (10-1,000/second). ${ }^{29}$ Oscillatory analysis of formulations was performed in the linear viscoelastic region to determine storage modulus $\left(\mathrm{G}^{\prime}\right)$ and loss modulus $\left(\mathrm{G}^{\prime \prime}\right)$. Frequency-sweep analysis was performed at $1 \mathrm{~Pa}$ amplitude at a frequency range of $0.1-10 \mathrm{~Hz}$ (0.3 mm gap). ${ }^{30,31}$

\section{In vitro release studies}

Plx or Chi gels ( 2 g) containing 10 mg Gem-HCl-loaded MSs were put into dialysis membrane tubes (Spectra/Por regenerated cellulose, molecular weight cutoff 12,000-14,000 Da). Dialysis membrane tubes were placed into $100 \mathrm{~mL} \mathrm{pH} 6.5$ PBS to mimic slightly acidic conditions of urine and stirred at $300 \mathrm{rpm}\left(37^{\circ} \mathrm{C} \pm 0.1^{\circ} \mathrm{C}\right)$ At predetermined time intervals, samples were withdrawn and drug content analyzed using $\operatorname{UPLC}(n=6)$.

\section{Determination of release mechanism}

The data were fitted to Peppas's equation and best-fit parameters calculated to determine the release mechanism of formulations: $:^{32}$

$$
\log \left(M_{t} / M_{\infty}\right)=\log k+n \cdot \log t
$$

where $\mathrm{M}_{\mathrm{t}} / \mathrm{M}_{\infty}$ is the fractional release, $\mathrm{k}$ the diffusional constant, and $\mathrm{n}$ the diffusional exponent that characterizes the drug-release mechanism.

\section{Ex vivo permeation studies}

Ex vivo permeation studies were performed on freshly excised bovine bladder mucosa with Franz-type diffusion cells. Briefly, mucosa was mounted on diffusion cells, formulations placed in a donor compartment, and the receptor compartment filled with pH 6.5 PBS (20 mL). Samples were taken from the receptor compartment at predetermined time intervals, and the permeated amount of Gem- $\mathrm{HCl}$ was determined with UPLC $(n=6)$. At the end of ex vivo permeation study, the excess formulation was removed and the mucosa fixed in 4\% neutral-buffered formalin. Standard procedures were applied to prepare $4 \mathrm{~mm}$-thick tissue sections, specimens were stained with $\mathrm{H} \& \mathrm{E}$, and mucosa samples were evaluated histopathologically with a microscope (Olympus BX50) to evaluate tissue damage to healthy mucosa. ${ }^{33}$

\section{Cytotoxic assay of formulations}

The cytotoxic effects of aqueous Gem-HCl, Gem-HClloaded MSs and Gem-HCl-loaded or blank MS containing and suspended in saline gels were evaluated by living cell counting. For this purpose, both RT4 (ATCC HTB2TM) and T24 (ATCC HTB4TM) cells were seeded in 12-well plates $\left(1.5 \times 10^{5}\right.$ cells/well $)$ and allowed to attach for 24 hours. Then, they were treated with different concentrations $(0.1-100 \mu \mathrm{M})$ of saline containing $\mathrm{Gem}-\mathrm{HCl}$, saline containing $\mathrm{Gem}-\mathrm{HCl}-$ loaded MSs, blank MSs suspended in saline, suspended in saline Plx or Chi gels containing Gem-HCl-loaded MSs and Plx or Chi gels containing blank MSs. Following 48 hours of exposure, the treatments were removed and cells washed with fresh McCoy's 5A medium (Thermo Fisher Scientific). Then, cells were trypsinized with PBS disaggregated with a pipette. Harvested cells were stained with trypan blue dye and counted under microscopy (Olympus IX71) by two independent investigators using hemocytometry. Viable (unstained) cells have intact cell membranes that exclude trypan dyes, whereas unviable (stained) cells take up this dye. For each 
concentration of $\mathrm{Gem}-\mathrm{HCl}$ or each formulation, the number of viable cells per milliliter was calculated.

Cells were also incubated in culture medium alone and served as a control for cell viability. Cell viability was calculated as a percentage of the absorbance reading of compounds compared to control readings. For statistical analysis, the cell-growth inhibition potency of formulations is expressed as $\mathrm{IC}_{50}$ values. $\mathrm{IC}_{50}$ was computed by nonlinear regression using GraphPad Prism 5.0 software. Cell death caused by the maximum concentration $(100 \mu \mathrm{M})$ applied to cells was regarded as inhibition percentage. Data are shown as mean $\pm \mathrm{SD}$ of six experiments.

\section{In vivo studies}

For in vivo studies, Sprague Dawley rats and $N$-butyl- $N$-(4hydroxybutyl)nitrosamine (BBN), a chemical carcinogen, was used to generate the bladder cancer model. During the in vivo study, the animals were controlled regularly in terms of health status (ie, diet situation, weight loss). Rats with a median weight of 300-350 g were selected as the experimental animal model. They were maintained in cages at $22^{\circ} \mathrm{C}-24^{\circ} \mathrm{C}$ with a 12 -hour/12-hour dark/light cycle and humidity of $55 \%$ with free access to water and food, fed ad libitum, and randomly divided into eleven experimental groups, with each group comprising seven rats (Table 1).

Bladder tumors were induced by adding $0.05 \% \mathrm{BBN}$ to freely available drinking water in dark bottles three times a week for 20 weeks. After 1 week without treatment, rats were given weekly intravesical instillations of formulations for 4 weeks. For intravesical administration, rats were anesthetized with weight-adjusted intraperitoneal doses of chloral hydrate $(400 \mathrm{mg} / \mathrm{kg})$. Bladders were emptied and washed with saline three times before drug instillation. Intravesical instillation was applied using a 17-gauge cannula.

Table I Experimental design of rat population for in vivo studies

\begin{tabular}{|c|c|}
\hline Animal groups & Rats, $\mathbf{n}$ \\
\hline I. Negative control (tumor ${ }^{-}$, treatment ${ }^{+}$) & 7 \\
\hline 2. Positive control (tumor ${ }^{+}$, treatment ${ }^{-}$) & 7 \\
\hline 3. Saline containing Gem-HCl & 7 \\
\hline 4. Saline containing blank MSs & 7 \\
\hline 5. Saline containing Gem-HCl-loaded MSs & 7 \\
\hline 6. Plx gel containing Gem-HCl & 7 \\
\hline 7. Plx gel containing blank MSs & 7 \\
\hline 8. Plx gel containing Gem-HCl-loaded MSs & 7 \\
\hline 9. Chi gel containing Gem-HCl & 7 \\
\hline 10. Chi gel containing blank MSs & 7 \\
\hline II. Chi gel containing Gem-HCl-loaded MSs & 7 \\
\hline
\end{tabular}

Abbreviations: Gem, gemcitabine; MSs, microspheres; Plx, poloxamer; Chi, chitosan.
Separate groups were treated with the different formulations, and $\mathrm{Gem}-\mathrm{HCl}$ doses were given as $4 \mathrm{mg}$ in $0.5 \mathrm{~mL}$ formulations. Animals were observed daily and clinical signs noted. Antitumor efficacy was determined by survival rate and histopathology of tumor-induced bladders after treatment.

At the end of the study, animals were killed with an overdose of chloral hydrate and bladders removed. Bladder tissue samples were immediately inserted into $4 \%$ neutral buffered formalin. The samples were subsequently processed with conventional techniques. H\&E-stained slides were reviewed under standard light microscopy. Histopathological alterations were assessed by an experienced pathologist blinded to the experimental groups and efficacy of treatment assessed. The "neoplasmic process" score in urothelial epithelium was assessed: normal was graded 0 , urothelial hyperplasia (flat and/or papillary) was graded 1, urothelial dysplasia and hyperplasia were graded 2, urothelial neoplasm with low malignancy potency was graded 3 , urothelial carcinoma papillary (low grade) was graded 4 , urothelial carcinoma papillary (high grade) was graded 5, and urothelial carcinoma in situ/urothelial carcinoma (high grade, early invasive) was graded 6 . In vivo studies were performed in accordance with the Turkish law for the protection of animals and were approved by the local ethical committee of the Kobay laboratory animals research and breeding unit (approval number 151, July 11, 2015, Ankara, Turkey).

\section{Stability studies}

Formulation stability was studied by storing samples at three different temperatures and relative humidity $\left(\mathrm{RH} ; 5^{\circ} \mathrm{C} \pm 2^{\circ} \mathrm{C}\right.$, $\left.25^{\circ} \mathrm{C} \pm 5^{\circ} \mathrm{C} / 60 \% \mathrm{RH}, 40^{\circ} \mathrm{C} \pm 5^{\circ} \mathrm{C} / 75 \% \mathrm{RH}\right)$. They were inspected visually for organoleptic properties, and $\mathrm{Gem}-\mathrm{HCl}$ amounts were evaluated at days 15, 30, and 60 .

\section{Statistical analysis}

Statistical data analysis was performed using Student's $t$-test with $P<0.05$ as the minimal level of significance.

\section{Results and discussion}

Conventional bladder cancer treatment with systemic administration of chemotherapeutic drugs is highly ineffective, since only a small fraction of the drug reaches the affected site. ${ }^{34}$ Therefore, development of novel drug-delivery systems, especially for high-risk non-muscle-invasive bladder cancer, is an important topic considering the currently available options. Bladder is an especially appropriate organ for local application, because it is easily approached from outside the body. Therefore, among several proposed strategies, 
intravesical administration might be the most convenient clinical application to ensure maximal delivery of therapeutic agents at the site of the disease, to improve efficacy, and to minimize systemic side effects of antineoplastic agents. However, short dwelling time of drugs in the bladder and the low drug permeability of urothelium are the main factors that limit the success of the treatment. The efficacy of intravesical treatment might be increased by prolonging the residence time of the drug inside the bladder. By this way, drugs can attach to the urinary bladder wall and penetrate it for extended periods. For these reasons, the present study describes the preparation of mucoadhesive Gem-HCl-loaded MSs to provide a sustained-release profile, prolong residence time, and enhance efficiency for bladder cancer. In addition, MSs were dispersed in mucoadhesive Chi or in situ Plx gels for intravesical administration and comprehensive in vitro/ ex vivo/in vivo evaluations performed.

\section{FTIR analysis}

Data obtained from FTIR analysis were found to be compatible with the literature findings, and there was no interaction between the active substance and the polymers (Figure 1).

\section{Preparation and characterization of microspheres}

MSs were successfully prepared by solvent evaporation. ${ }^{15}$ For preformulation studies, different stirring rates and times were used for preparation of MSs (ie, 40 minutes at 1,000 rpm, 60 minutes at 1,000 rpm, 40 minutes at $750 \mathrm{rpm}$, and 60 minutes at $750 \mathrm{rpm}$ ). The results obtained showed that stirring rate and time were important parameters for this technique. For instance, the shapes of the particles were irregular at high stirring speed of 1,000 rpm. Also, 40 minutes of stirring time was not enough to disperse the inner phase in the outer phase at $750 \mathrm{rpm}$ (data not shown). Similar results have been reported previously, and various manufacturing parameters (apparatus design, type of stirrer, stirring speed, viscosity of emulsion phases, and stabilizer concentration) were shown to affect particle characteristics. ${ }^{35,36}$ By keeping drug and polymer amounts constant, spherical particles with narrow size distribution and good surface characteristics were obtained when MPs were prepared for 60 minutes at $750 \mathrm{rpm}$, and so these parameters were selected as optimum for the preparation.

The particle size and distribution of MSs were determined by laser-light scattering. Particle size is expressed as

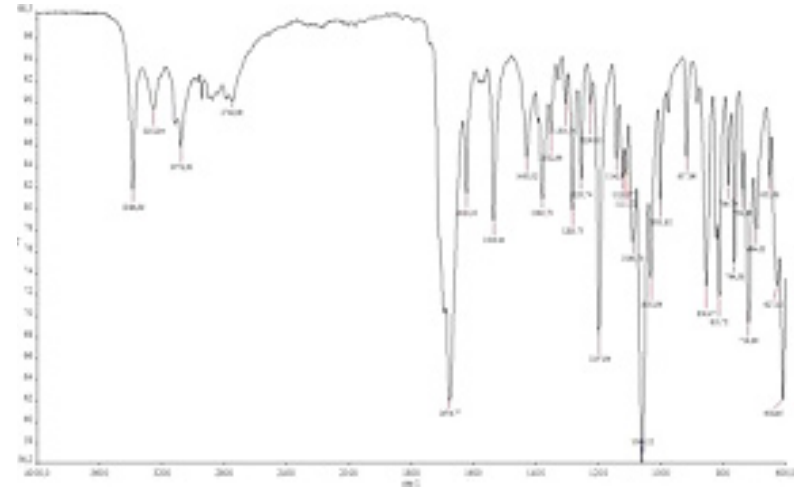

Gem-HCI

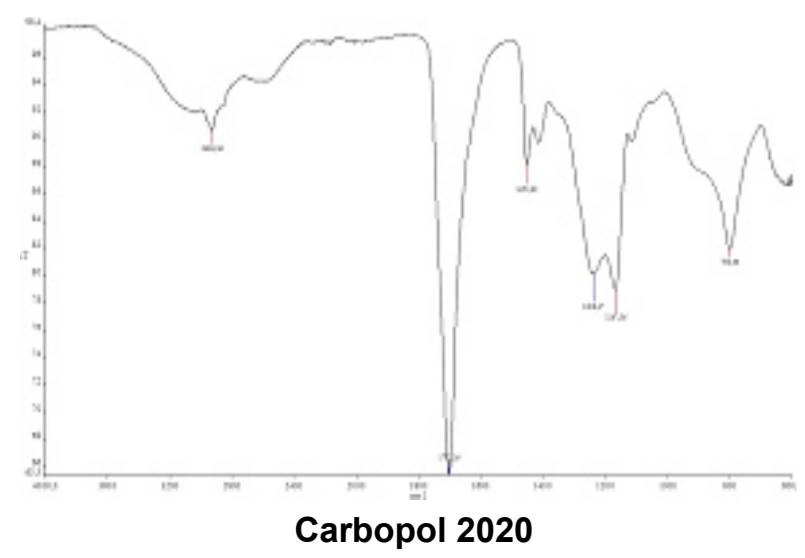

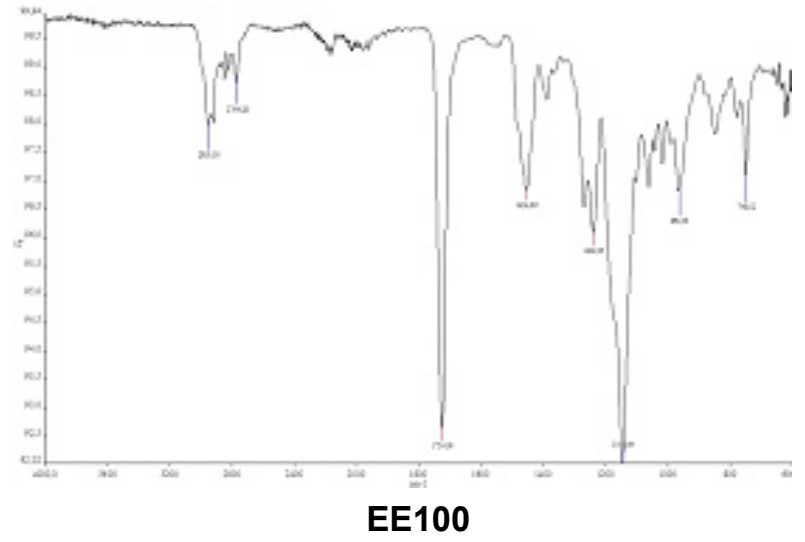

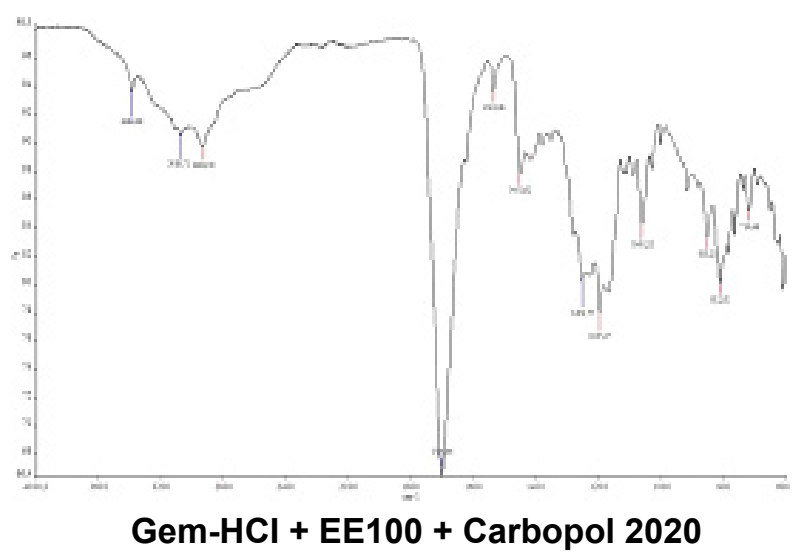

Figure I Fourier-transform infrared spectra of Gem-HCl, EE 100, Carbopol 2020, and their mixture. Abbreviations: Gem, gemcitabine; EEI00, Eudragit EI00. 
Table 2 Particle-size distribution of formulations

\begin{tabular}{lllll}
\hline \multicolumn{5}{l}{ Blank MS formulation (sieved from I $25 \mu \mathrm{m})$} \\
\hline & $\mathbf{D}_{10}(\mu \mathrm{m})$ & $\mathbf{D}_{50}(\mu \mathrm{m})$ & $\mathbf{D}_{90}(\mu \mathrm{m})$ & Span \\
\hline Mean & 49.100 & 98.400 & 156.000 & 1.086 \\
SD (\%) & 0.300 & 0.849 & 3.320 & \\
RSD (\%) & 0.610 & 0.863 & 2.130 & \\
\hline \multicolumn{5}{l}{ Gem-HCl-loaded MS formulation (sieved from I25 $\mu \mathrm{m})$} \\
\hline Mean & I20.000 & I80.000 & 263.000 & 0.794 \\
SD (\%) & 0.807 & 0.365 & 1.100 & \\
RSD (\%) & 0.670 & 0.202 & 0.416 & \\
\hline
\end{tabular}

Abbreviation: MS, microsphere.

mean volume diameter in micrometers and characterized by $10 \%, 50 \%$ and $90 \%$ undersized diameters: $\mathrm{D}_{10}, \mathrm{D}_{50}$, and $\mathrm{D}_{90}$. $\mathrm{D}_{50}$ was defined as the diameter where half the particles' size was below this value, and was considered the mean diameter. The results obtained showed that $50 \%$ of the Gem-HClloaded MSs were $<180 \mu \mathrm{m}$, whereas $50 \%$ of the blank MSs were $<98.4 \mu \mathrm{m}$, with significantly narrower size distribution (Table 2). The surface morphology of the MSs was observed by scanning electron microscopy, and most MSs were shown to be spherical with rough surface morphology (Figure 2).

Gem-HCl-loaded MSs were produced with high drugencapsulation efficiency and loading capacity for a watersoluble active substance. Encapsulation efficiency and loading capacity were found to be $82.657 \% \pm 5.817 \%$ and $12.501 \% \pm 0.881 \%$, respectively. Also, MPs were produced with high production yield ( $86.94 \%$ for total produced MSs and $47.615 \%$ for particles in $125 \mu \mathrm{m}$ fraction). Considering the acceptable encapsulation efficiency, loading capacity, and high production yield, it can be concluded that solvent evaporation is a simple and suitable technique for producing Gem-HCl-loaded MSs.

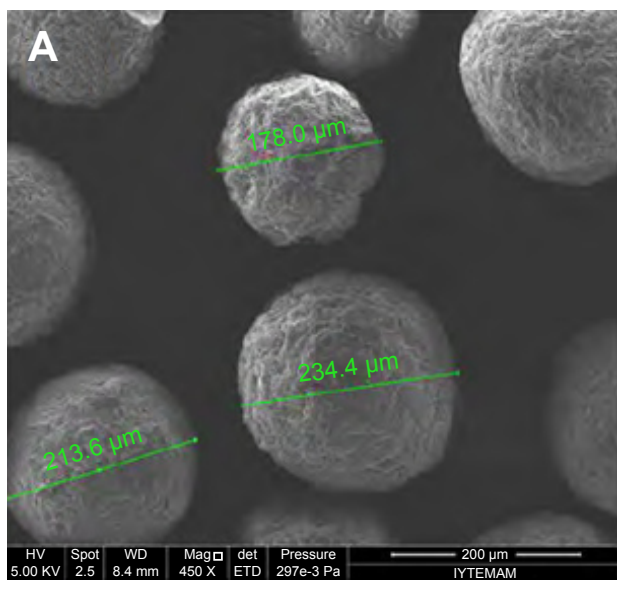

\section{Preparation of Chi and Plx gels}

To modify the release profile of $\mathrm{Gem}-\mathrm{HCl}$, obtain sustainedrelease properties, prolong residence time, and increase therapeutic efficiency, MSs were suspended in two different gels for intravesical administration. The use of an in situ gel formulation allows for easy administration of the liquid formulation into the bladder. It also provides prolonged contact between the drug and the affected tissue, due to the in situ phase transition to a gel on the surface of the bladder. Another important advantage of in situ gel system is the formation of a uniformly thin layer of gel at the application site. This thin layer does not cause any disturbance in urine flow or affect bladder filling. ${ }^{37}$ In one of our previous studies, different Plx 407 and 188 combinations were evaluated for gelation temperature/time, mechanical, rheological, and bioadhesive properties. The results showed that a $20 \% \mathrm{Plx}$ 407 and 10\% Plx 188 mixture was an optimal in situ gelling system for mucosal applications. ${ }^{23}$ Therefore, in this study a 20\% Plx 407 and 10\% Plx 188 mixture was chosen as the in situ carrier for Gem-HCl MSs.

Designing intravesical formulations using bioadhesive biomaterials that are strongly adhered to urothelial cells prevents the carrier from being washed away during urine voiding and increases the residence time of the drug at the target site. Therefore, MSs were also suspended in bioadhesive GHI gel to prolong residence in the bladder. To this end, high-molecular-weight $\mathrm{Chi}$ at $2 \%$ concentration was chosen as the gel base because of its strong mucoadhesiveness, proper mechanical and rheological characteristics, and extended mucosal retention time. ${ }^{21}$

One of the important limitations of intravesical drug delivery is the dilution of instilled drug formulations

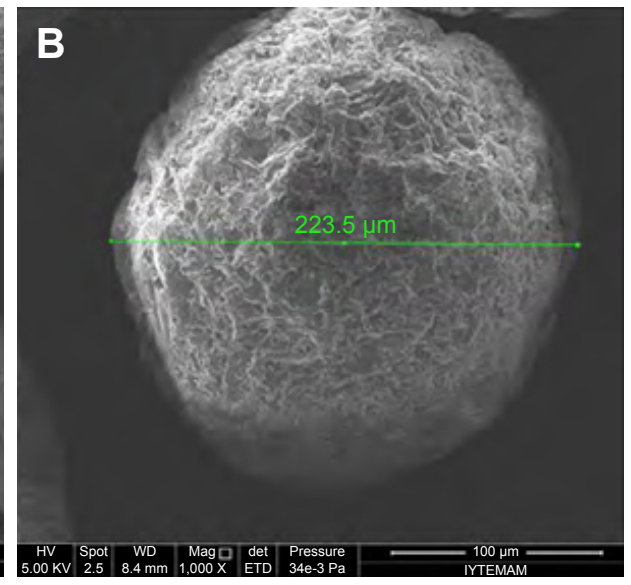

Figure 2 Scanning electron microscopy of Gem-HCl-loaded MSs.

Note: (A) Magnification 450x; (B) magnification I,000×.

Abbreviations: Gem, gemcitabine; MSs, microspheres; Mag, magnification; HV, high voltage; WD, working distance; det, detector of secondary electrons; ETD, EverhartThornley detector. 
with urine. The maximum urine volume in the bladder is generally 250-350 mL, and because of incomplete emptying, nearly $50 \mathrm{~mL}$ urine generally stays, even after voiding. Chemotherapeutic drugs are generally applied with intravesical installation of 20-60 mL formulation. Therefore, in vivo conditions in the bladder were simulated by dilution of formulations with artificial urine (Tyrode solution) at a 1:1 ratio, and changes in properties of in situ Plx gel and mucoadhesive Chi gel investigated in detail. ${ }^{16}$

\section{Characterization of gels}

The Chi and Plx gels containing Gem-HCl-loaded MSs were characterized in terms of their of gelation temperature, viscosity, mechanical, syringeability, bioadhesive, and rheological properties. Characterization studies were also performed with gel formulations without MSs and gel formulations diluted with Tyrode solution to see whether there were a change in the gel structure.

\section{Gelation temperature and time of in situ Plx gels}

The suitable temperature range for mucosal application has been reported to be $30^{\circ} \mathrm{C}-36^{\circ} \mathrm{C} .{ }^{38} \mathrm{Also}$, the gelling temperature of the formulation should be $>25^{\circ} \mathrm{C}$ to avoid difficulties in manufacturing, handling, and administration at room temperature. ${ }^{39}$ The bladder temperature is around $37^{\circ} \mathrm{C},{ }^{40}$ hence we aimed at preparing thermoreversible gel formulations that might be in a gel state at $30^{\circ} \mathrm{C}-36^{\circ} \mathrm{C}$ and a liquid state $<25^{\circ} \mathrm{C}$. In this way, the thermoreversibility of the in situ gel formulation would contribute to increased contact time in the bladder. The results showed that the gelation temperatures of $\mathrm{Plx}$ gel and Gem-HCl MS-loaded Plx gel were $34.09^{\circ} \mathrm{C} \pm 1.54^{\circ} \mathrm{C}$ and $36.53^{\circ} \mathrm{C} \pm 2.02^{\circ} \mathrm{C}$, respectively, and these values indicated that the prepared formulations were in liquid state at room temperature and transformed into the gel state after instillation in the bladder. On the other hand, the gelation temperatures of Plx gel-Tyrode and MS-loaded Plx gel-Tyrode mixtures were significantly increased and found to be $51.73^{\circ} \mathrm{C} \pm 0.99^{\circ} \mathrm{C}$ and $47.95^{\circ} \mathrm{C} \pm 0.76^{\circ} \mathrm{C}$, respectively. This unfavorable result showed that the presence of urine affected the gelation temperature of the formulation and the in situ gel formulation lost its gel structure in the bladder.

In addition, the gelation-time results support our findings, and dilution with Tyrode solution significantly extended the gelation time of the formulations. The gelation times of Plx gel, MS-loaded Plx gel, Plx gel-Tyrode solution, and MS-loaded Plx gel-Tyrode solution were found to be $327.67 \pm 25.88$ seconds, $324.67 \pm 34.25$ seconds,
$457 \pm 4$ seconds, and $419.45 \pm 18.49$ seconds, respectively. To overcome these problems, emptying the bladder before drug instillation, suppression of the urine-production rate by the kidneys, or regulation of fluid intake before and after drug administration are highly recommended before the administration of in situ gels. ${ }^{15}$

Mechanical, syringeability, and bioadhesive properties Intravesical formulations should have suitable mechanical properties for easy administration and patient compliance, such as easy removal from the catheter, high spreadability on the bladder mucosa, and strong mucoadhesion. Textureprofile analyses allow the gathering of information about the gel structure and evaluation of the mechanical properties of the formulations. ${ }^{27}$ In this study, the mechanical properties of the formulations were characterized in terms of hardness, compressibility, adhesiveness, elasticity, and cohesiveness. Hardness value should be low to allow easy administration and good spreadability. Compressibility value should be low to remove the formulation from the catheter easily. Adhesiveness can be related to mucoadhesive properties and should be high. Elasticity represents the return rate of the deformed sample to its beginning condition. Finally, cohesiveness shows the effect of repeated shearing stresses on the formulations.

As shown in Table 3, similar hardness values were obtained at $25^{\circ} \mathrm{C}$ for all formulations. However, due to gelation-temperature properties, Plx gel alone and Plx gel containing MSs showed 10.5-fold and 8.3-fold higher hardness values than Chi gel alone and Chi gel containing MSs at $37^{\circ} \mathrm{C}$, respectively. Depending on increasing temperature, compressibility and adhesiveness values of Chi gels containing MSs decreased significantly, and this was thought to be associated with the thermal motion of the polymer molecules. ${ }^{41}$ No significant temperature-dependent change was observed with cohesiveness, hardness, or elasticity values of Chi gels. These results were in accordance with rheological evaluations. In contrast, Plx gels strengthened, and mechanical properties were improved by increasing the temperature from $25^{\circ} \mathrm{C}$ to $37^{\circ} \mathrm{C}$. Blank and $\mathrm{Plx}$ gels containing MSs exhibited the highest hardness and compressibility values at $37^{\circ} \mathrm{C}$, supporting the results obtained by oscillatory rheology (ie, increased elastic behavior represented by $\mathrm{G}^{\prime \prime}$ in Figure 3). Higher adhesiveness could mean greater adhesion at the mucosal surface, which is a desirable characteristic required to increase drug retention in the bladder. ${ }^{42,43}$ Based on the results, it appeared that $\mathrm{Plx}$ gels containing $\mathrm{MSs}$ at $37^{\circ} \mathrm{C}$ could meet these desirable mechanical properties; nevertheless, 
Table 3 Mechanical, syringeability, bioadhesion, and viscosity values of Chi and Plx gels $(n=6)$

\begin{tabular}{|c|c|c|c|c|c|c|c|c|}
\hline Formulation & $\begin{array}{l}\text { Hardness, } \\
\mathbf{N}\end{array}$ & $\begin{array}{l}\text { Compressibility, } \\
\text { N.second }\end{array}$ & $\begin{array}{l}\text { Adhesiveness, } \\
\mathrm{N} \cdot \text { second }\end{array}$ & Cohesiveness & Elasticity & $\begin{array}{l}\text { Syringeability, } \\
\text { N.mm }\end{array}$ & $\begin{array}{l}\text { Bioadhesion, } \\
\mathrm{mN} \cdot \mathrm{mm}\end{array}$ & $\begin{array}{l}\text { Viscosity, } \\
\text { cP }\end{array}$ \\
\hline \multicolumn{9}{|l|}{ Chi gel } \\
\hline $25^{\circ} \mathrm{C}$ & $0.014 \pm 0.001$ & $0.042 \pm 0.007$ & $0.121 \pm 0.028$ & $1.008 \pm 0.024$ & $0.896 \pm 0.112$ & $130.140 \pm 2.857$ & - & $1,200 \pm 0$ \\
\hline $37^{\circ} \mathrm{C}$ & $0.018 \pm 0.002$ & $0.075 \pm 0.011$ & $0.119 \pm 0.039$ & $1.016 \pm 0.005$ & $1.04 \mathrm{I} \pm 0.037$ & - & $2,066.18 \pm 236.34$ & $973.67 \pm 2.08$ \\
\hline \multicolumn{9}{|c|}{ Chi gel containing MSs } \\
\hline $25^{\circ} \mathrm{C}$ & $0.016 \pm 0.00$ & $0.120 \pm 0.004$ & $0.085 \pm 0.013$ & $1.029 \pm 0.015$ & $1.061 \pm 0.052$ & $131.340 \pm 7.564$ & - & $836 \pm 1$ \\
\hline $37^{\circ} \mathrm{C}$ & $0.017 \pm 0.003$ & $0.052 \pm 0.011$ & $0.053 \pm 0.004$ & $0.979 \pm 0.020$ & $0.958 \pm 0.073$ & - & $2,4|0.60 \pm 285.3|$ & $789.67 \pm 1.53$ \\
\hline \multicolumn{9}{|c|}{ Chi gel-Tyrode solution } \\
\hline $37^{\circ} \mathrm{C}$ & $0.006 \pm 0.00 \mathrm{I}$ & $0.011 \pm 0.002$ & $0.007 \pm 0.001$ & $0.987 \pm 0.012$ & $0.999 \pm 0.207$ & - & $\mathrm{I}, 067.63 \pm 364.98$ & $90.1 \pm 0.1$ \\
\hline \multicolumn{9}{|c|}{ Chi gel containing MS-Tyrode solution } \\
\hline $37^{\circ} \mathrm{C}$ & $0.008 \pm 0$ & $0.018 \pm 0.001$ & $0.007 \pm 0$ & $1.000 \pm 0$ & $0.987 \pm 0.048$ & - & $1,676.50 \pm 248.29$ & $102.67 \pm 0.58$ \\
\hline \multicolumn{9}{|l|}{ PIx gel } \\
\hline $25^{\circ} \mathrm{C}$ & $0.018 \pm 0$ & $0.114 \pm 0.003$ & $0.006 \pm 0.001$ & $1.058 \pm 0.027$ & $0.95 I \pm 0.021$ & $99.830 \pm 1.510$ & - & $636 \pm 0$ \\
\hline $37^{\circ} \mathrm{C}$ & $0.189 \pm 0.009$ & $0.355 \pm 0.019$ & $0.297 \pm 0.017$ & $1.008 \pm 0.005$ & $0.905 \pm 0.017$ & - & $1,951.74 \pm 186.17$ & $-*$ \\
\hline \multicolumn{9}{|c|}{ PIx gel containing MSs } \\
\hline $25^{\circ} \mathrm{C}$ & $0.010 \pm 0$ & $0.026 \pm 0$ & $0.005 \pm 0$ & $1.000 \pm 0$ & $0.978 \pm 0.042$ & $120.584 \pm 4.184$ & - & $722.67 \pm 1.53$ \\
\hline $37^{\circ} \mathrm{C}$ & $0.14 I \pm 0.008$ & $0.430 \pm 0.080$ & $0.230 \pm 0.039$ & $1.331 \pm 0.121$ & $0.992 \pm 0.025$ & - & $2,700.72 \pm 137.82$ & -* \\
\hline \multicolumn{9}{|c|}{ PIx gel-Tyrode solution } \\
\hline $37^{\circ} \mathrm{C}$ & $0.005 \pm 0$ & $0.006 \pm 0.001$ & $0.004 \pm 0$ & $1.025 \pm 0.05 \mid$ & $0.974 \pm 0.084$ & - & $\mathrm{I}, 072.62 \pm 5 \mathrm{I} .76$ & $27.2 \pm 0.1$ \\
\hline \multicolumn{9}{|c|}{ Plx gel containing MS-Tyrode solution } \\
\hline $37^{\circ} \mathrm{C}$ & $0.008 \pm 0$ & $0.028 \pm 0.001$ & $0.006 \pm 0.002$ & $1.013 \pm 0.033$ & $1.034 \pm 0.145$ & - & $\mathrm{I}, 408.53 \pm 87.46$ & $38.23 \pm 0.15$ \\
\hline
\end{tabular}

Notes: *Could not be measured because of the high viscosity of the sample; bioadhesion studies and evaluation of formulations diluted with Tyrode solution studied only at $37^{\circ} \mathrm{C}$ to mimic in vivo conditions; syringeability studies conducted only at $25^{\circ} \mathrm{C}$ to mimic room temperature. Data presented as mean $\pm \mathrm{SD}$.

Abbreviations: Chi, chitosan; Plx, poloxamer; MS, microsphere.

further in vitro bioadhesion tests were performed to confirm initial results. The addition of MSs or the presence of Tyrode solution strongly weakened the mechanical properties of both mucoadhesive Chi and in situ Plx gels, but the most significant decrease was seen in Plx gels. These results showed that the presence of urine in the bladder is an important factor that may affect the retention of formulations.

Syringeability can be considered the ability of a formulation to be easily administered by a catheter, and this property optimizes usability. ${ }^{27}$ Therefore, the work required to expel

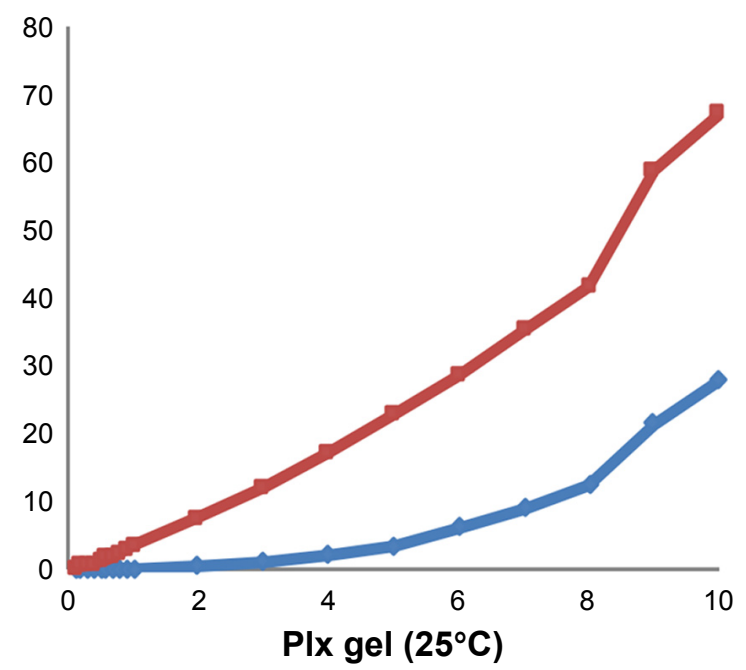

formulations from a catheter was evaluated at $25^{\circ} \mathrm{C}$, and the results showed that consistently with the viscosity studies, the syringeability values of chitosan gels were higher than Plx gels. It can be concluded that the results obtained are in agreement with the viscosity and rheological studies and Plx gels are more easily applied with a catheter than Chi gels.

Intravesical drug-delivery systems could be made more effective by using bioadhesive materials that attach to the mucous membrane of the urothelium. This allows the formulation to be retained at the site of action for longer

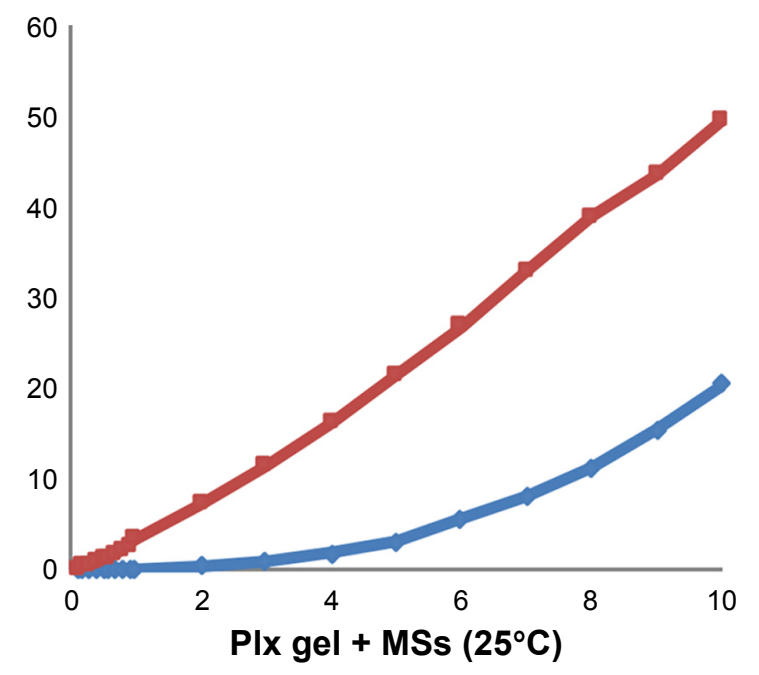

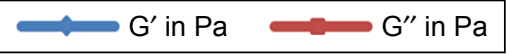

Figure 3 (Continued) 

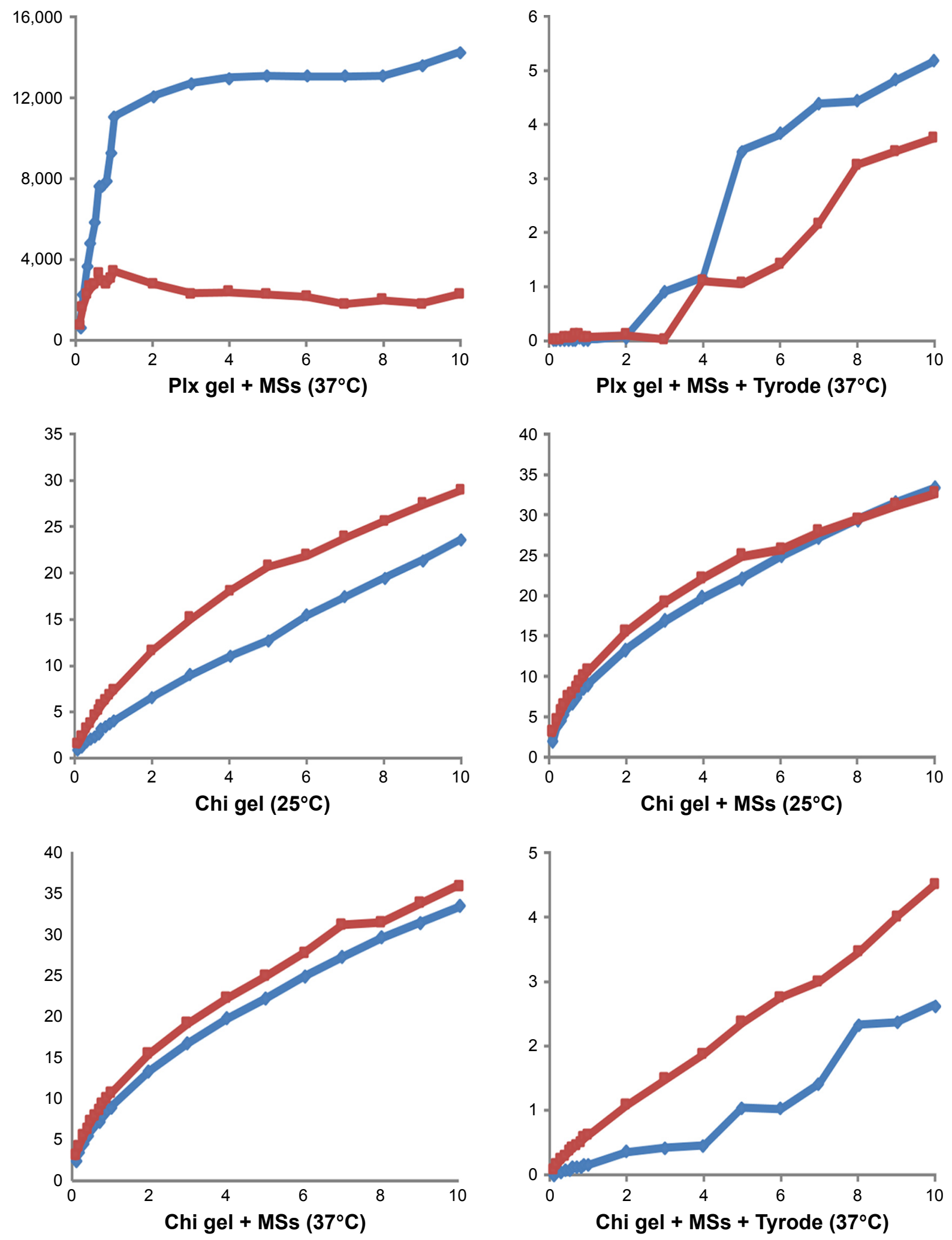

$\longrightarrow \mathrm{G}^{\prime}$ in $\mathrm{Pa} \longrightarrow \mathrm{G}^{\prime \prime}$ in $\mathrm{Pa}$

Figure 3 Frequency-dependent changes of the viscoelastic properties of $\mathrm{Chi}$ versus Plx gels at $25^{\circ} \mathrm{C}$ and $37^{\circ} \mathrm{C} \pm 0.1^{\circ} \mathrm{C}(\mathrm{n}=6)$. Notes: Frequency $(\mathrm{Hz})$ on $x$-axis; moduli $\mathrm{G}^{\prime} ; \mathrm{G}^{\prime \prime}(\mathrm{Pa})$ on $y$-axis.

Abbreviations: Chi, chitosan; Plx, poloxamer; MSs, microspheres. 
duration and ensures sustained and enhanced contact with the mucous layer. ${ }^{20,37,44}$ Bioadhesive formulations must fulfill three basic criteria: they should have rapid attachment or adhesion to the bladder wall after instillation in the bladder, they must not obstruct the flow of urine or any normal functions of the bladder, and they should be able to stay attached to the affected site, even after voiding of urine. In our study, the bioadhesive properties of the formulations were determined from the area of force-distance graphs obtained with the TA-TX Plus texture analyzer using freshly excised bovine-bladder mucosa. According to the results (Table 3), bioadhesive properties of our formulations were affected significantly by adding MSs or in the presence of Tyrode solution. At the beginning, Chi- and Plx-gel formulations had similar bioadhesive properties. Addition of MSs caused a significant increase in bioadhesion values of the gels, and this increase was more pronounced with Plx gel than Chi gel. On the other hand, when gel formulations were diluted with Tyrode solution, bioadhesive values of both gel formulations were significantly decreased. Plx and chitosan gels containing MSs showed 1.9 and 1.4 times higher bioadhesive values than their mixture with Tyrode solution. In addition, the results showed that MS-loaded Chi-gel formulations still had slightly higher bioadhesive properties than MS-loaded Plx gel. Finally, it can be concluded that both of the formulations maintained their bioadhesive properties on isolated urinary bladder tissue, even having been fully hydrated, and this may be promising for intravesical applications.

\section{Viscosity studies}

Viscosity affects mechanical properties of semisolid formulations and plays an important role in controlling drug release. ${ }^{45}$ In this study, we aimed to obtain suitable viscosity values to provide optimum fluidity at room temperature and for easy transduction through a catheter into the bladder. ${ }^{46}$ The viscosity of Chi gels decreased 1.23 times with increasing temperature (Table 3 ). The negative dependence of viscosity on Chi-gel temperature could be explained by enhanced chain flexibility and reduced root-mean-square unperturbed end-to-end distance of the polymer chains with increasing temperature. ${ }^{26,47}$ In addition, viscosity values of Chi gels were decreased with the incorporation of MSs at both $25^{\circ} \mathrm{C}$ and $37^{\circ} \mathrm{C} \pm 0.1^{\circ} \mathrm{C}$, and these results showed good agreement with literature findings. ${ }^{21,42}$

The viscosity of Plx gels with and without MSs increased at $37^{\circ} \mathrm{C} \pm 0.1^{\circ} \mathrm{C}$, due to the thermogelling property of $\mathrm{Plx}$ molecules, as expected. At $37^{\circ} \mathrm{C} \pm 0.1^{\circ} \mathrm{C}$, the viscosity of both
Plx gels increased too much and could not be measured with a vibration viscometer. MS addition did not cause a significant change in Plx-gel viscosity. As mentioned previously, all formulations were diluted with Tyrode solution for simulation of in vivo conditions. This dilution caused significant loss of viscosity in all the gel formulations, and this decrease was more pronounced with Plx gels.

\section{Rheological measurements}

It is well known that rheological properties of formulations affect both ease of application and retention within an application site; therefore, they are very important parameters for choosing the optimum intravesical formulation. ${ }^{21}$ Therefore, detailed rheology studies were carried out on gel formulations and their dilutions with Tyrode solution at both room and body temperature.

First, flow properties of the formulations were determined with continuous shear analysis. The Plx formulations showed Newtonian flow at $25^{\circ} \mathrm{C} \pm 1^{\circ} \mathrm{C}$ and non-Newtonian plastic flow at $37^{\circ} \mathrm{C} \pm 1^{\circ} \mathrm{C}$, as expected (data not shown). This confirmed that $\mathrm{Plx}$-gel formulations were viscous liquid at room temperature and formed a semisolid gel at body temperature. At temperatures over the sol-gel transition temperature, this type of non-Newtonian flow is typical for Plx formulations. ${ }^{48}$ On the other hand, Chi-gel formulations had non-Newtonian plastic behavior with shear-thinning properties at both $25^{\circ} \mathrm{C}$ and $37^{\circ} \mathrm{C}$ (data not shown). This type of rheological behavior is desirable for intravesical drug administration, because when force is applied it will result in a decrease in viscosity and make the gel easy to be pushed through a catheter at room temperature. ${ }^{49}$

In addition, dilution with Tyrode solution caused a significant decrease in viscosity of all formulations. Plx gels continued the Newtonian-type flow even at $37^{\circ} \mathrm{C}$ when diluted with Tyrode solution, which could be explained by a significant decrease in viscosity. Since this may be unfavorable for intravesical application, it demonstrates the importance of evacuation of the bladder prior to in situ gel administration with regard to the formulation's permanence. On the other hand, it was determined that dilution of Chi gels with Tyrode solution did not change their flow property, although it caused a marked decrease in viscosity. This was considered a positive feature for intravesical formulations prepared with Chi, as the pseudoplasticity demonstrates the continuity of gel formation.

Furthermore, to get comprehensive information on the rheological state of formulations, oscillation measurements 
were performed to yield information about viscous and elastic properties of the formulations. Oscillation tests are dynamic methods for determining the viscoelastic properties of the tested material in its rheological ground state. To get information about the viscous and elastic behavior of the system and the network structure formed by particle-particle interactions, a frequency-sweep test has to be performed. A frequency-sweep test is a dynamic test measuring the response of a system as a function of frequency at constant stress amplitude. It reveals the storage modulus $\mathrm{G}^{\prime}$ (elastic response) and the loss modulus $G^{\prime \prime}$ (viscous response). ${ }^{50}$

Figure 3 shows the plots of $\mathrm{G}^{\prime}$ and $\mathrm{G}^{\prime \prime}$ as a function of frequency at two different temperature values. Formulations prepared with Chi exhibited viscoelastic properties and low gel strength. Mechanical spectra with frequency dependence of $G^{\prime}$ and $G^{\prime \prime}$ and smaller separation between the two moduli indicated that Chi formulations could be considered weak gels at both temperatures. ${ }^{43} \mathrm{G}^{\prime}$ and $\mathrm{G}^{\prime \prime}$ moduli of Plx formulations were low at room temperature and rose significantly at body temperature. At $37^{\circ} \mathrm{C}, \mathrm{G}^{\prime}$ dominated $\mathrm{G}^{\prime \prime}$ for all frequencies and the gap between the two moduli became wider, indicating stronger gel strength. MS-loaded Plx gel was found to be frequency-independent, exhibiting an elastic structure (strong gel, $\mathrm{G}^{\prime}>\mathrm{G}^{\prime \prime}$ ) at $37^{\circ} \mathrm{C}$. Finally, the rheological behavior of Chi and $\mathrm{Plx}$ formulations diluted with Tyrode solution was evaluated, and liquid-solid behavior of macromolecular solutions was observed for all diluted gels. These results were in accordance with the reduced viscosity values and weak mechanical properties of Chi and Plx formulations diluted with Tyrode solution.

\section{In vitro release studies}

The in vitro release profile of $\mathrm{Gem}-\mathrm{HCl} \mathrm{MSs}$ and gel formulations containing $\mathrm{Gem}-\mathrm{HCl} \mathrm{MSs}$ were examined in PBS (pH 6.5) at $37^{\circ} \mathrm{C} \pm 0.1^{\circ} \mathrm{C}$, and results are displayed in Figure 4. According to results, $\mathrm{Gem}-\mathrm{HCl}$ release from MSs can be defined as fast (nearly $85 \%$ within 60 minutes), which was probably the consequence of good swelling and permeability properties of EE100 above $\mathrm{pH}$ 5. This rapid release of $\mathrm{Gem}-\mathrm{HCl}$ from $\mathrm{MSs}$ may result in drug loss with urinary excretion.

The release profile of MS-loaded gel formulations indicated that nearly $30 \%$ of $\mathrm{Gem}-\mathrm{HCl}$ was released from the $\mathrm{Plx}$ gel containing MSs and 50\% of Gem-HCl released from the Chi gel containing MSs within 60 minutes. These results showed that Chi or Plx gels significantly slowed the release rate of Gem-HCl. Sustained release was obtained for Gem$\mathrm{HCl}$ with gel formulations during 3 hours, and both of the gel formulations can be defined as effective for modifying release properties of Gem-HCl. Plx gel slowed down drug release further than Chi gel because of the higher viscosity values at $37^{\circ} \mathrm{C}$. The increase in gel viscosity reduced the Gem-HCl release rate, because the gel-dissolution time extended and drug diffusion through gel matrix was prolonged. This sustained and slow release might be an important advantage of Plx gels, because slower release of intravesically administered drugs ensures extended drug presence in the bladder without the need for intermittent catheterization, increases drug efficacy, and reduces or eliminates harmful drug side effects. ${ }^{51,52}$ For determination of release mechanism, n, k and $r^{2}$ values calculated with Peppas's equation are listed in Table 4.

\section{Ex vivo permeation studies}

The potential permeation profiles of the formulations were determined on freshly excised bovine-bladder mucosa, and the results are shown in Figure 4. When the permeation profiles were investigated, it was observed that the permeated ratio of $\mathrm{Gem}-\mathrm{HCl}$ from $\mathrm{MSs}$ (76.74\%) was higher than MS-loaded Plx and Chi gels, similarly to in vitro release profiles. This result was again probably due to very good swelling and permeability of EE100. The permeated percentage of $\mathrm{Gem}-\mathrm{HCl}$ within 60 minutes from MS-loaded Chi and Plx gel reached $25.77 \%$ and $7.54 \%$, respectively. This low ratio of permeated $\mathrm{Gem}-\mathrm{HCl}$ from gels can be explained by the interaction of gels with bladder mucosa. This result can indicate retention of $\mathrm{Gem}-\mathrm{HCl}$ in the mucosa layer and probably cause a local effect of MS-loaded gel formulations. ${ }^{53}$

\section{Histopathological evaluation}

Ex vivo histopathological examinations were performed to observe the effect of the formulations on the bladder mucosa. The results of the histopathological evaluation of the bladder mucosa are shown in Figure 5. Firstly, it was determined that no pathological features were recorded in the urothelial epithelium, lamina propria, or muscularis propria of untreated empty mucosa which was placed directly into formalin and the mucosa treated with the buffer solution instead of the formulation for control purposes. A layer covering the surface of the urothelial epithelium was observed at urothelia with Chi-gel formulation containing MPs, and this layer was associated with the applied formulation. No pathological features were noted with this formulation in the lamina propria or muscularis propria.

Urothelia with Plx gel containing MPs showed a tendency of refraction and spillage of urothelial epithelium at the light-microscopy level. No pathological features were noted in the lamina propria or muscularis propria. Finally, 

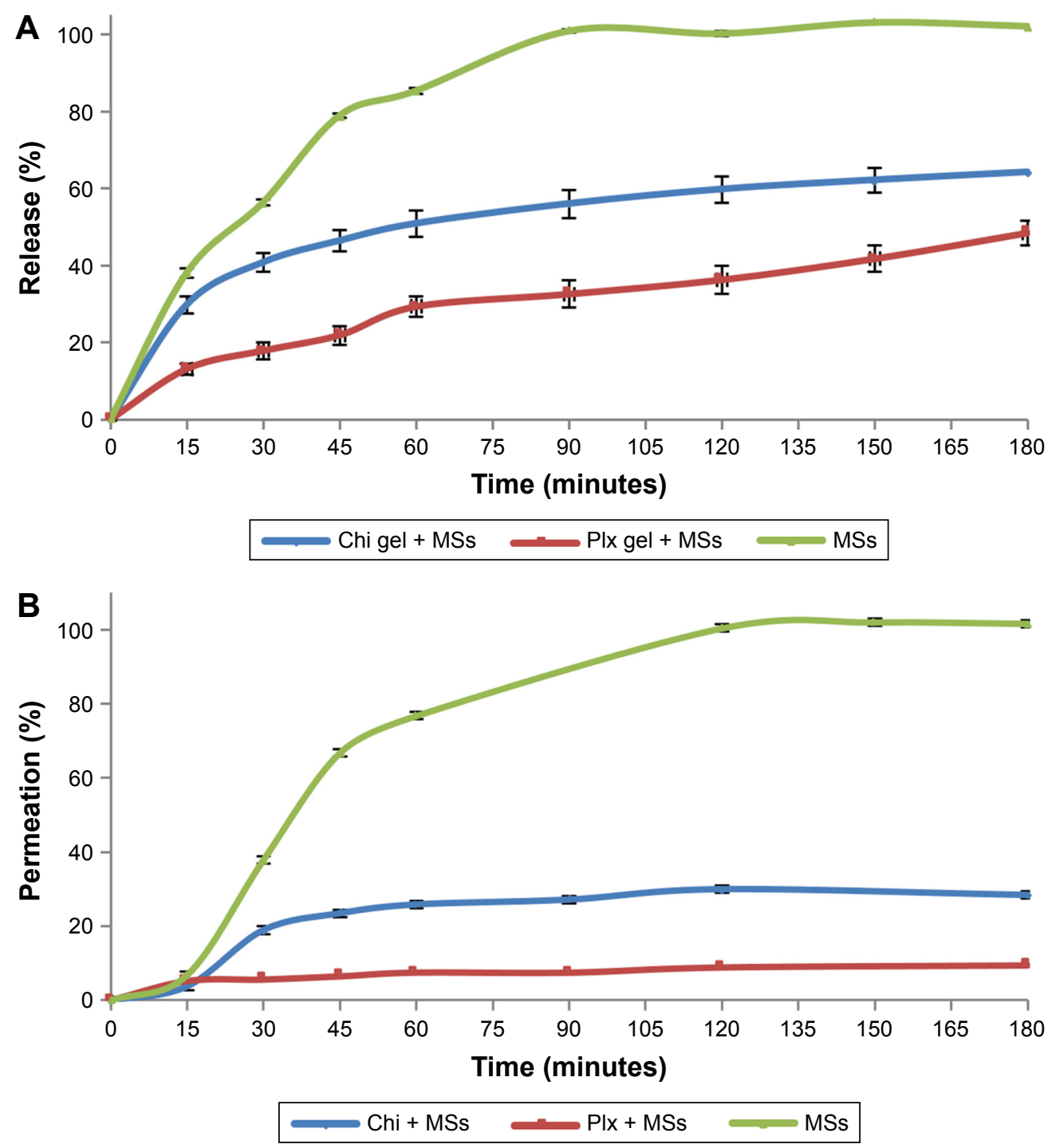

Figure $4 \mathrm{ln}$ vitro release (A) and ex vivo permeation (B) profiles of Gem-HCl from MS-loaded Chi gel, Plx gel, and MSs in PBS of pH 6.5. Abbreviations: Gem, gemcitabine; MS, microsphere; Chi, chitosan; Plx, poloxamer.

the results obtained suggest that Gem-HCl-loaded MSs and Gem-HCl MSs containing Chi and Plx gels did not cause any damage to healthy bladder mucosa, and these formulations might thus be regarded as safe.

\section{Cytotoxic assay for formulations}

Gem-HCl solution and Gem-HCl MS- and Gem-HCl MSloaded gel formulations prepared for intravesical administration were evaluated in two different bladder cancer cell

Table 4 Release parameters of $\mathrm{Gem}-\mathrm{HCl}$ from formulations

\begin{tabular}{llll}
\hline & $\begin{array}{l}\text { Release } \\
\text { component (n) }\end{array}$ & $\begin{array}{l}\text { Kinetic } \\
\text { constant (log k) }\end{array}$ & $\boldsymbol{r}^{2}$ \\
\hline MSs & 0.565 & 0.916 & 0.999 \\
Plx gel containing MSs & 0.462 & 0.573 & 0.999 \\
Chi gel containing MSs & 0.545 & 0.832 & 0.920 \\
\hline
\end{tabular}

Abbreviations: Gem, gemcitabine; MSs, microspheres; Plx, poloxamer; Chi, chitosan. lines - T24 (ATCC HTB-4TM) and RT4 (ATCC HTB$2 \mathrm{TM}$ ) - to assess cytotoxic effects. These cell lines are used widely as respective superficial and invasive models of human bladder cancer. RT4 is representative of noninvasive superficial cancer and T24 representative of invasive bladder tumor with a metastatic profile. ${ }^{54}$ Firstly, the potencies of cell-growth inhibition of the formulations $\left(\mathrm{IC}_{50}\right.$ values $)$ were determined for RT4 and T24 cell lines, and results are shown in Table 5. Gem-HCl solution was found to be more potent on RT4 cells than T24 cells in terms of cytotoxicity ( $\mathrm{IC}_{50}$ $12.55 \pm 0.62$ and $24.35 \pm 1.05 \mu \mathrm{M}$, respectively). The difference in cytotoxic effects of $\mathrm{Gem}-\mathrm{HCl}$ solution in the two cell types could have been caused by genetic differences between the cell lines. ${ }^{55} \mathrm{~T} 24$ has much faster metabolism and divides more readily than RT4. ${ }^{56}$ T24 cells are also more malignant than RT4 cells. However, the Gem-HCl-loaded MSs were found 

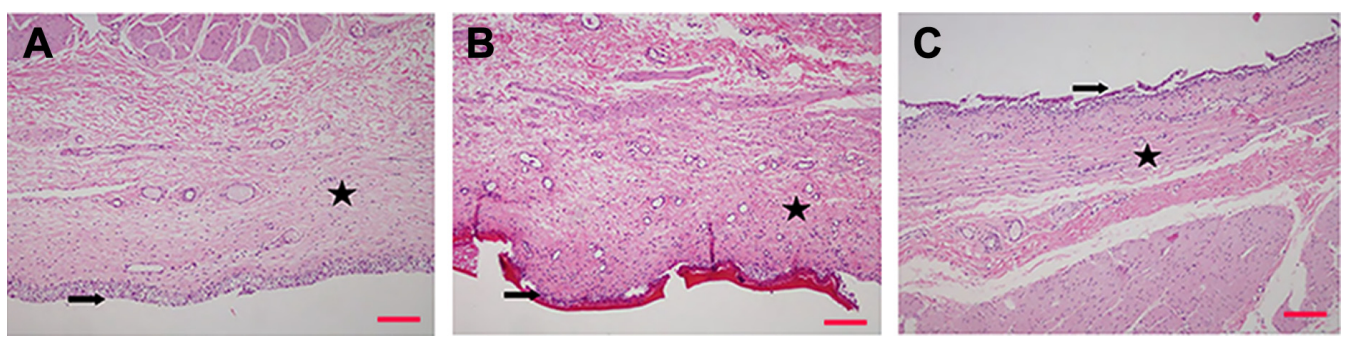

Figure 5 Microscopic images of bovine bladder mucosa.

Notes: (A) Healthy bladder mucosa; (B) bladder mucosa treated with MS-loaded Chi gel; (C) bladder mucosa treated with MS-loaded Plx gel. H\&E staining, magnification 40x; $\rightarrow$ urothelium, $\star$ lamina propria. Scale bar $200 \mu \mathrm{m}$.

Abbreviations: MS, microsphere; Chi, chitosan; Plx, poloxamer.

to be more potent than aqueous $\mathrm{Gem}-\mathrm{HCl}$ solution in both cell lines. It can be conceivable that MS formulations have high potency at the same dose compared with a commercial aqueous formulation. Empty MS-loaded gel formulations had no cytotoxic effects on either cell line (data not shown). In addition, Gem-HCl-loaded MSs exhibited greater cytotoxicity against T24 cells $(24.35-15.88 \mu \mathrm{M})$, which represented more malignancy than in RT4 cells $(12.55-10.16 \mu \mathrm{M})$. This suggested that the Gem-HCl-loaded MS formulation was more selective for T24 malignant bladder cells. The Gem$\mathrm{HCl}$ MS-loaded Plx-gel formulation was more potent than the Chi-gel formulation in both cell lines. Plx-loaded gemcitabine gels were almost as potent as the $\mathrm{Gem}-\mathrm{HCl}$ solution. It should be noted that a gel formulation will be in contact with tumor cells for a longer time than an aqueous solution of gemcitabine in the bladder. It is expected that prolonged exposure of the urothelium to a drug increases the efficacy of the treatment. Farr et al found a 10,000-100,000-fold selectivity of gemcitabine treatment on cancer (RT4, T24) relative to noncancer (UROTSA) urothelial cell lines. ${ }^{57}$ Therefore, it could be expected that in vivo application of MSs and their gel formulations would be comparable to conventionally used $\mathrm{Gem}-\mathrm{HCl}$ in patients suffering from bladder cancer.

\section{In vivo studies}

In vivo animal studies for intravesical formulations of $\mathrm{Gem}-\mathrm{HCl}$ were started after cytotoxic assays. At the end

Table $5 \mathrm{IC}_{50}$ values $(\mu \mathrm{M})$ of $\mathrm{Gem}-\mathrm{HCl}$ solution, Gem-HCl MS-, and $\mathrm{Gem}-\mathrm{HCl}$ MS-loaded Chi and Plx gel formulations on RT4 and T24 cells

\begin{tabular}{lll}
\hline & RT4 cells & T24 cells \\
\hline Gem-HCl & $12.55 \pm 0.62$ & $24.35 \pm 1.05$ \\
Gem-HCl MSs & $10.16 \pm 1.10$ & $15.88 \pm 1.21$ \\
Gem-HCl MS-loaded Chi gel & $13.11 \pm 2.81$ & $71.75 \pm 52.77$ \\
Gem-HCl MS-loaded Plx gel & $11.73 \pm 1.97$ & $26.84 \pm 3.98$ \\
\hline
\end{tabular}

Note: Data presented as mean \pm SD.

Abbreviations: Gem, gemcitabine; MS, microsphere; Chi, chitosan; Plx, poloxamer. of 20 weeks, randomly selected rats were killed using an overdose of chloral hydrate to see if they had carcinoma in situ, and bladders removed and fixed in $4 \%$ neutral buffered formalin. After histopathological procedures had been applied, the degree of tissue damage was determined using light microscopy. Although different lesions were observed with varied characteristics, disease symptoms were observed at the base of the bladder of each rat (Figure 6). As a result of this evaluation, the second stage for in vivo studies (the treatment process) was started.

During the treatment period, $4 \mathrm{mg} \mathrm{Gem}-\mathrm{HCl}$ in $0.5 \mathrm{~mL}$ formulation were administered to rats once weekly during 4 weeks. After the last administration, one week was spent empty, and at the end of the fifth week the rats were killed. Following routine histopathology procedure, bladders were examined under light microscopy. Histopathologically, the changes in the bladder mucosa were scored as normal urothelial epithelium, hyperplasia, dysplasia/carcinoma in situ, or urothelial carcinoma. Developmental characteristics (papillary-nodular), invasiveness, and squamous features were evaluated in urothelial carcinomas. The term "urothelial carcinoma" was used for all cases with and without glandular squamous areas.

Urothelial carcinomas including squamous areas were seen with histopathological examination of the control group (group 2). The development of multifocal papillary lesions was anterior, and invasion was not evaluated for this group. For two of the rats on which Gem-HCl-containing Plx-gel formulations were administered, dysplasia findings were more pronounced (group 6). In addition, lesions accompanied by peripheral mucosa were also detected in animals with marked dysplasia findings.

It was observed that urothelial mucosa was normal in all rats that had been treated with Plx gel containing GemHCl-loaded MSs (group 8). When the results obtained from the group administered Chi gel containing Gem-HCl-loaded 


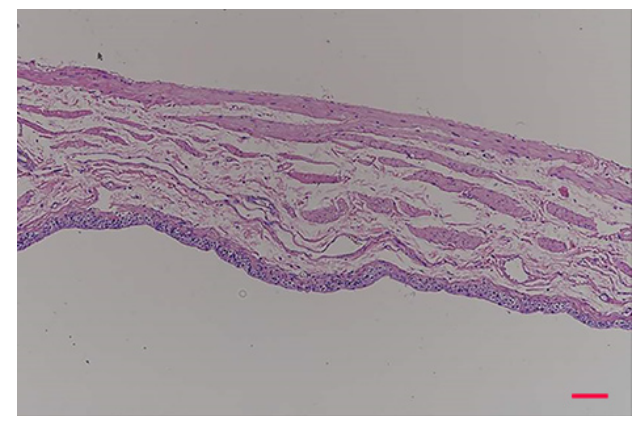

Normal urothelial epithelium

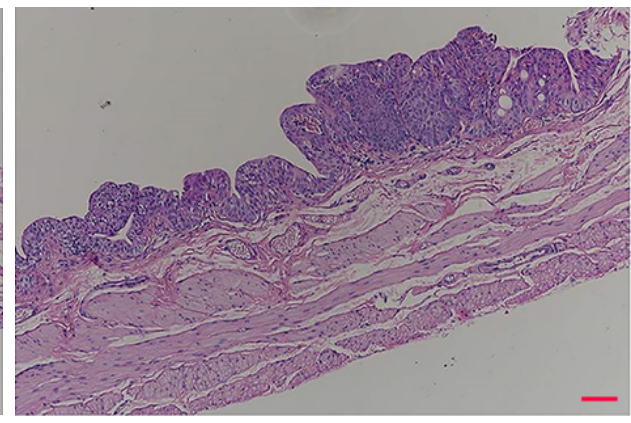

Urothelial dysplasia/carcinoma in situ

Figure 6 Microscopic images of normal urothelial epithelium and urothelial dysplasia/carcinoma in situ. Scale bar $200 \mu \mathrm{m}$.

MPs were examined (group 11), findings in favor of focal minimal urothelial dysplasia were observed in the mucosa. When the results obtained from the groups of Chi and Plx gels containing empty MSs were examined (groups 7 and 10), no treatment finding was found. Also, two of the rats administered saline containing $\mathrm{Gem}-\mathrm{HCl}$ (group 3) had evidence of hyperplasia, with thickening of mucosal epithelium in one and findings of dysplasia were observed in the other. In the remaining animals, carcinoma findings and lesions accompanying the surrounding mucosa were detected.

Among the rats to which empty MSs had been administered in saline (group 4), there were findings in favor of hyperplasia due to thickening of the mucosal epithelium in the dysplasia findings and accompanying lesions in the surrounding mucosa. Among the rats to which Gem-HCl-loaded MSs had been applied in saline (group 5), mucosa was common in two, whereas epithelial thickening was observed in favor of hyperplasia in one. The findings of dysplasia were also observed in both. One of them draws attention, with widespread lesions that accompanied the surrounding mucosa. Summarizing the results of in vivo studies, intravesical treatment with once-weekly Plx gel with Gem-HCl-loaded MSs was found to be more effective than the others.

\section{Stability studies}

Stability tests were performed with all the formulations at $5^{\circ} \mathrm{C} \pm 2^{\circ} \mathrm{C}, 25^{\circ} \mathrm{C} \pm 5^{\circ} \mathrm{C} / 60 \% \mathrm{RH}$, and $40^{\circ} \mathrm{C} \pm 5^{\circ} \mathrm{C} / 75 \% \mathrm{RH}$. General appearance and organoleptic properties of MSs did not change significantly in 2 months during stability studies. The proportion of active substance in the MPs kept at $5^{\circ} \mathrm{C} \pm 2{ }^{\circ} \mathrm{C}, 25^{\circ} \mathrm{C} \pm 5^{\circ} \mathrm{C} / 60 \% \mathrm{RH}$, and $40^{\circ} \mathrm{C} \pm 5^{\circ} \mathrm{C} / 75 \% \mathrm{RH}$ was found to be $72.27 \%, 72.92 \%$, and $65.20 \%$ at the end of the 2 months, respectively (Table 6). Stability studies were also performed with gel formulations containing MPs (data not shown). Firstly, gels were evaluated in terms of their $\mathrm{pH}$ values. There was no significant change in $\mathrm{pH}$ values of the formulations at these temperatures during this time period. Gel formulations were also evaluated in terms of their viscosity and Plx gels examined in terms of gelation temperature and gelation time. According to the obtained results, a marked decrease in viscosity values was observed in formulations kept at $40^{\circ} \mathrm{C} \pm 5^{\circ} \mathrm{C}$ and $75 \% \mathrm{RH}$. In addition, it was observed that the gelation temperature and time of Plx gels increased significantly. For these reasons, it was concluded that it would be appropriate to keep all formulations in the refrigerator and protected against high temperature and humidity.

\section{Conclusion}

Direct instillation of drugs into the bladder is an efficient alternative to systemic delivery, since it reduces side effects, prevents first-pass effects, and consequently allows a more effective treatment. However, this method is limited by excessive drug loss during voiding. To increase the residence time of the drug in the bladder and achieve a more effective intravesical treatment, Gem-HCl MSs were prepared and loaded in gel formulations in the present study. The results obtained revealed that MS-loaded gel formulations exhibited suitable properties for intravesical administration of Gem$\mathrm{HCl}$. According to the results, Chi and Plx gels might be alternative carriers for intravesical administration of GemHCl-loaded MSs. However, with their strong gel structure, desirable mechanical, bioadhesive, and in vitro and ex vivo

Table $6 \mathrm{Gem}-\mathrm{HCl}$ amounts in MSs $(\mu \mathrm{g})$

\begin{tabular}{llll}
\hline & $\mathbf{5}^{\circ} \mathbf{C} \pm \mathbf{2}^{\circ} \mathbf{C}$ & $\begin{array}{l}\mathbf{2 5}^{\circ} \mathbf{C} \pm \mathbf{5}^{\circ} \mathbf{C}, \\
\mathbf{6 0 \%} \mathbf{R H}\end{array}$ & $\begin{array}{l}\mathbf{4 0}^{\circ} \mathbf{C} \pm \mathbf{5}^{\circ} \mathbf{C}, \\
\mathbf{7 5 \%} \mathbf{R H}\end{array}$ \\
\hline Beginning & $9.042 \pm 1.323$ & $9.042 \pm 1.323$ & $9.042 \pm 1.323$ \\
Day 15 & $8.991 \pm 1.664$ & $8.915 \pm 1.080$ & $8.162 \pm 1.546$ \\
Day 30 & $8.967 \pm 0.940$ & $8.808 \pm 1.666$ & $7.826 \pm 1.944$ \\
Day 60 & $6.535 \pm 0.864$ & $6.594 \pm 1.236$ & $5.896 \pm 0.856$ \\
\hline
\end{tabular}

Abbreviations: Gem, gemcitabine; MSs, microspheres; RH, relative humidity 
sustained-release properties, Plx-gel formulations came forward as the better carrier for Gem-HCl MSs. In addition, according to the cell-culture studies, Gem-HCl MS-loaded Plx gel showed greater cytotoxicity than Chi-gel formulations in both cell types. However, when diluted with artificial urine to mimic the conditions in bladder, Plx gels lost their in situ gelling properties at body temperature. To overcome this problem, such strategies as emptying the bladder before drug instillation, suppression of urine-production rate by the kidneys, and regulation of fluid intake before and after drug administration are recommended.

\section{Acknowledgments}

This study was supported by the Scientific and Technological Research Council of Turkey (grant TUBITAK-112/S/293). The authors would also like to thank the TR Prime Ministry State Planning Organization Foundation (project 09/ DPT/001).

\section{Disclosure}

The authors report no conflicts of interest in this work.

\section{References}

1. Wang S, Zhao J, Hu J, et al. Phase-changeable and bubble-releasing implants for highly efficient HIFU-responsive tumor surgery and chemotherapy. J Mater Chem B. 2016;4(46):7368-7378.

2. Wang S, Zhao J, Yang H, et al. Bottom-up synthesis of WS2 nanosheets with synchronous surface modification for imaging guided tumor regression. Acta Biomater. 2017;58:442-454.

3. Wu C, Zhao J, Hu F, et al. Design of injectable agar-based composite hydrogel for multi-mode tumor therapy. Carbohydr Polym. 2018;180: $112-121$.

4. Moreira JM, Ohlsson G, Gromov P, et al. Bladder cancer-associated protein, a potential prognostic biomarker in human bladder cancer. Mol Cell Proteomics. 2010;9(1):161-177.

5. Ferlay J, Soerjomataram I, Dikshit R, et al. Cancer incidence and mortality worldwide: sources, methods and major patterns in GLOBOCAN 2012. Int J Cancer. 2015;136(5):E359-E386.

6. Mattioli F, Curotto A, Manfredi V, et al. Intravesical gemcitabine in superficial bladder cancer: a phase II safety, efficacy and pharmacokinetic study. Anticancer Res. 2005;25(3C):2493-2496.

7. Kondylis FI, Demirci S, Ladaga L, et al. Outcomes after intravesical bacillus Calmette-Guérin are not affected by substaging of high grade $\mathrm{T} 1$ transitional cell carcinoma. Int J Urol. 2000;163(4):1120-1123.

8. Erdoğar N, Iskit AB, Eroğlu H, Sargon MF, Mungan NA, Bilensoy E. Antitumor efficacy of bacillus Calmette-Guérin loaded cationic nanoparticles for intravesical immunotherapy of bladder tumor induced rat model. J Nanosci Nanotechnol. 2015;15(12):10156-10164.

9. Herr HW, Bajorin DF, Scher HI. Neoadjuvant chemotherapy and bladder-sparing surgery for invasive bladder cancer: ten-year outcome. J Clin Oncol. 1998;16(4):1298-1301.

10. Shimizu H, Akasaka S, Suzuki S, Akimoto M, Shimada T. Preferential gene transfer to $\mathrm{BBN}$-induced rat bladder tumor by simple instillation of adenoviral vector. Urology. 2001;57(3):579-584.

11. Cozzi PJ, Bajorin DF, Tong W, et al. Toxicology and pharmacokinetics of intravesical gemcitabine: a preclinical study in dogs. Clin Cancer Res. 1999;5(9):2629-2637.
12. Witjes JA, van der Heijden AG, Vriesema JL, Peters GJ, Laan A, Schalken JA. Intravesical gemcitabine: a phase 1 and pharmacokinetic study. Eur Urol. 2004;45(2):182-186.

13. Gontero P, Tizzani A. Intravesical gemcitabine: state of the art. Eur Urol Suppl. 2007;6(14):809-815.

14. Bergman AM, Pinedo HM, Peters GJ. Determinants of resistance to $2^{\prime}, 2^{\prime}$-difluorodeoxycytidine (gemcitabine). Drug Resist Updat. 2002;5(1):19-33

15. Burjak M, Bogataj M, Velnar M, Grabnar I, Mrhar A. The study of drug release from microspheres adhered on pig vesical mucosa. Int J Pharm. 2001;224(1-2):123-130.

16. Şenyiğit ZA, Karavana SY, İlem-Özdemir D, et al. Design and evaluation of an intravesical delivery system for superficial bladder cancer: preparation of gemcitabine HCl-loaded chitosan-thioglycolic acid nanoparticles and comparison of chitosan/poloxamer gels as carriers. Int J Nanomedicine. 2015;10:6493-6507.

17. Au JL, Jang SH, Wientjes MG. Clinical aspects of drug delivery to tumors. J Control Release. 2002;78(1-3):81-95.

18. Shaikh R, Singh TR, Garland MJ, Woolfson AD, Donnelly RF. Mucoadhesive drug delivery systems. J Pharm Bioallied Sci. 2011; 3(1):89-100.

19. Hoare TR, Kohane DS. Hydrogels in drug delivery: progress and challenges. Polymer. 2008;49(8):1993-2007.

20. Lu S, Neoh KG, Kang ET, Mahendran R, Chiong E. Mucoadhesive polyacrylamide nanogel as a potential hydrophobic drug carrier for intravesical bladder cancer therapy. Eur J Pharm Sci. 2015;72: $57-68$.

21. Senyiğit ZA, Karavana SY, Eraç B, Gürsel O, Limoncu MH, Baloğlu E. Evaluation of chitosan based vaginal bioadhesive gel formulations for antifungal drugs. Acta Pharm. 2014;64(2):139-156.

22. Choi HG, Oh YK, Kim CK. In situ gelling and mucoadhesive liquid suppository containing acetaminophen: enhanced bioavailability. Int J Pharm. 1998;165(1):23-32.

23. Baloglu E, Karavana SY, Senyigit ZA, Guneri T. Rheological and mechanical properties of poloxamer mixtures as a mucoadhesive gel base. Pharm Dev Technol. 2011;16(6):627-636.

24. Chutipongtanate $S$, Thongboonkerd V. Systematic comparisons of artificial urine formulas for in vitro cellular study. Anal Biochem. 2010; 402(1):110-112.

25. Karavana SY, Rençber S, Şenyiğit ZA, Baloğlu E. A new in-situ gel formulation of itraconazole for vaginal administration. Pharmacol Pharm. 2012;3(4):417-426.

26. Jones DS, Woolfson AD, Djokic J. Texture profile analysis of bioadhesive polymeric semisolids: mechanical characterization and investigation of interactions between formulation components. J Appl Polym Sci. 1996;61(12):2229-2234.

27. Jones DS, Woolfson AD, Brown AF, Coulter WA, McClelland C, Irwin CR. Design, characterisation and preliminary clinical evaluation of a novel mucoadhesive topical formulation containing tetracycline for the treatment of periodontal disease. J Control Release. 2000; 67(2-3):357-368.

28. Turgut A, Tavman I, Chirtoc M, Schuchmann HP, Sauter C, Tavman S. Thermal conductivity and viscosity measurements of water-based $\mathrm{TiO}_{2}$ nanofluids. Int J Thermophys. 2009;30(4):1213-1226.

29. Jones DS, Woolfson AD, Brown AF. Textural, viscoelastic and mucoadhesive properties of pharmaceutical gels composed of cellulose polymers. Int J Pharm. 1997;151(2):223-233.

30. Andrews GP, Gorman SP, Jones DS. Rheological characterisation of primary and binary interactive bioadhesive gels composed of cellulose derivatives designed as ophthalmic viscosurgical devices. Biomaterials. 2005;26(5):571-580.

31. Andrews GP, Jones DS. Rheological characterization of bioadhesive binary polymeric systems designed as platforms for drug delivery implants. Biomacromolecules. 2006;7(3):899-906.

32. Peppas NA. Analysis of Fickian and non-Fickian drug release from polymers. Pharm Acta Helv. 1985;60(4):110-111. 
33. Gomez P, Gil ES, Lovett ML, et al. The effect of manipulation of silk scaffold fabrication parameters on matrix performance in a murine model of bladder augmentation. Biomaterials. 2011;32(30):7562-7570.

34. Nirmal J, Chuang YC, Tyagi P, Chancellor MB. Intravesical therapy for lower urinary tract symptoms. Urol Sci. 2012;23:70-77.

35. Pongbaibul Y, Maruyama K, Iwatsuru M. Formation and in-vitro evaluation of theophylline-loaded poly(methyl methacrylate) microspheres. J Pharm Pharmacol. 1988;40(8):530-533.

36. Haznedar S, Dortunç B. Preparation and in vitro evaluation of Eudragit microspheres containing acetazolamide. Int J Pharm. 2004; 269(1):131-140

37. Guhasarkar S, Banerjee R. Intravesical drug delivery: challenges, current status, opportunities and novel strategies. $J$ Control Release 2010;148(2):147-159.

38. Almomen A, Cho S, Yang $\mathrm{CH}$, et al. Thermosensitive progesterone hydrogel: a safe and effective new formulation for vaginal application. Pharm Res. 2015;32(7):2266-2279.

39. Cho E, Gwak H, Chun I. Formulation and evaluation of ondansetron nasal delivery systems. Int J Pharm. 2008;349(1-2):101-107.

40. Fallis WM. Monitoring urinary bladder temperature in the intensive care unit: state of the science. Am J Crit Care. 2002;11(1):38-45.

41. el-Hefian EA, Elgannoudi ES, Mainal A, Yahaya AH. Characterization of chitosan in acetic acid: rheological and thermal studies. TurkJ Chem. 2010;34:47-59.

42. Cevher E, Sensoy D, Taha MA, Araman A. Effect of thiolated polymers to textural and mucoadhesive properties of vaginal gel formulations prepared with polycarbophil and chitosan. AAPS PharmSciTech. 2008;9(3):953-965.

43. Ström A, Schuster E, Goh SM. Rheological characterization of acid pectin samples in the absence and presence of monovalent ions. Carbohydr Polym. 2014;113:336-343.

44. Tuğcu-Demiröz F, Acartürk F, Özkul A. Preparation and characterization of bioadhesive controlled-release gels of cidofovir for vaginal delivery. J Biomater Sci Polym Ed. 2015;26(17):1237-1255.

45. Hwang TL, Fang CL, Chen CH, Fang JY. Permeation enhancer-containing water-in-oil nanoemulsions as carriers for intravesical cisplatin delivery. Pharm Res. 2009;26(10):2314-2323.
46. Liu CW, Chang LC, Lin KJ, et al. Preparation and characterization of gelatin-based mucoadhesive nanocomposites as intravesical gene delivery scaffolds. Biomed Res Int. 2014;2014:473823.

47. Dumitriu S. Polymeric Biomaterials. 2nd ed. New York: Marcel Dekker; 2001.

48. Baloglu E, Karavana SY, Senyigit ZA, et al. In-situ gel formulations of econazole nitrate: preparation and in-vitro and in-vivo evaluation. J Pharm Pharmacol. 2011;63(10):1274-1282.

49. Chatta D, Cottrell L, Burnett B, Laverty G, McConville C. The use of water-soluble mucoadhesive gels for the intravesical delivery of epirubicin to the bladder for the treatment of non-muscle-invasive bladder cancer. J Pharm Pharmacol. 2015;67(10):1355-1362.

50. Lippacher A, Müller RH, Mäder K. Semisolid SLN dispersions for topical application: influence of formulation and production parameters on viscoelastic properties. Eur J Pharm Biopharm. 2002;53(2): 155-160.

51. Ricci EJ, Lunardi LO, Nanclares DM, Marchetti JM. Sustained release of lidocaine from poloxamer 407 gels. Int J Pharm. 2005;288(2): 235-244.

52. Betsiou M, Bantsis G, Zoi I, Sikalidis C. Adsorption and release of gemcitabine hydrochloride and oxaliplatin by hydroxyapatite. Ceram Int. 2012;38(4):2719-2724.

53. Nava G, Piñón E, Mendoza L, Mendoza N, Quintanar D, Ganem A. Formulation and in vitro, ex vivo and in vivo evaluation of elastic liposomes for transdermal delivery of ketorolac tromethamine. Pharmaceutics. 2011;3(4):954-970.

54. Vianna DR, Ruschel L, Dietrich F, et al 4-Methylcoumarins with cytotoxic activity against T24 and RT4 human bladder cancer cell lines. MedChemComm. 2015;6(5):c5md00039d.

55. O'Toole CM, Povey S, Hepburn P, Franks LM. Identity of some human bladder cancer cell lines. Nature. 1983;301(5899):429-430.

56. Zhao ZF, Wang K, Guo FF, Lu H. Inhibition of T24 and RT4 human bladder cancer cell lines by heterocyclic molecules. Med Sci Monit. 2017;23:1156-1164.

57. Farr ES, Chess-Williams R, McDermott CM. Gemcitabine: selective cytotoxicity, induction of inflammation and effects on urothelial function. Toxicol Appl Pharmacol. 2017;316:1-9.

\section{Publish your work in this journal}

Drug Design, Development and Therapy is an international, peerreviewed open-access journal that spans the spectrum of drug design and development through to clinical applications. Clinical outcomes, patient safety, and programs for the development and effective, safe, and sustained use of medicines are the features of the journal, which

\section{Dovepress}

has also been accepted for indexing on PubMed Central. The manuscript management system is completely online and includes a very quick and fair peer-review system, which is all easy to use. Visit http://www.dovepress.com/testimonials.php to read real quotes from published authors. 